\title{
Synthesis and Aqueous Self-assembly of ABCD Bottlebrush Block- Copolymers
}

\author{
Eman Ahmed, C. Tyler Womble and Marcus Weck* \\ Molecular Design Institute and Department of Chemistry, New York University, New York, NY 10003, United \\ States \\ Corresponding author: marcus.weck@,nyu.edu
}

Table of Contents

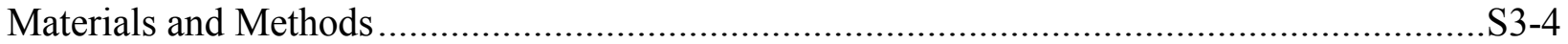

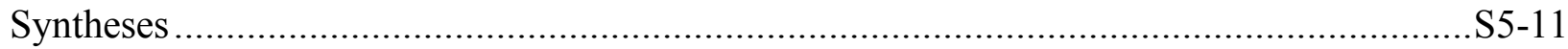

Grubbs' Third Generation Initiator ................................................................... S5

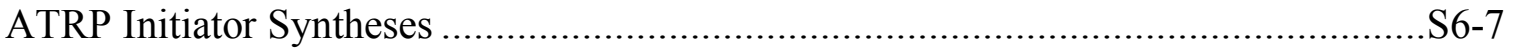

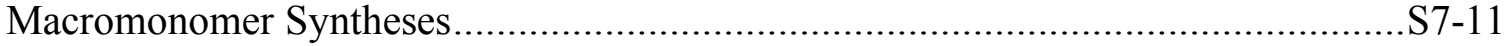

ROMP Polymerization Procedure ......................................................................... $111-13$

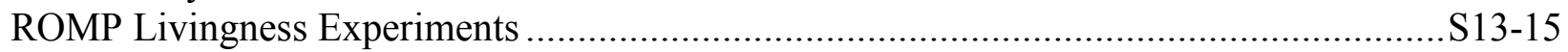

ROMP Kinetics Experiments............................................... 15 16

Figure S1. First order kinetic plots of macromonomers.......................... 16

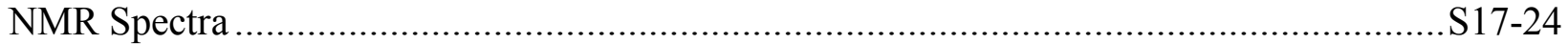

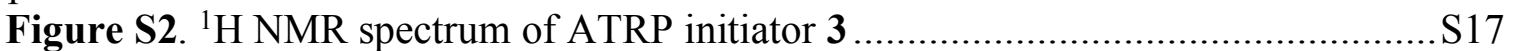

Figure S3. ${ }^{13} \mathrm{C}\left\{{ }^{1} \mathrm{H}\right\}$ NMR spectrum of the ATRP initiator 3 ................................... 17

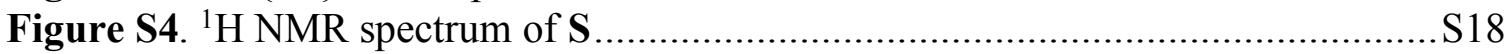

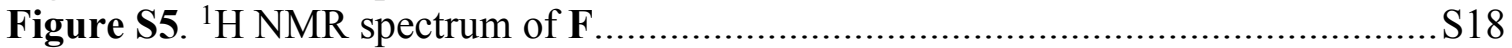

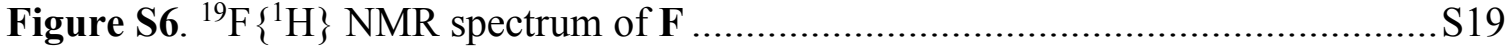

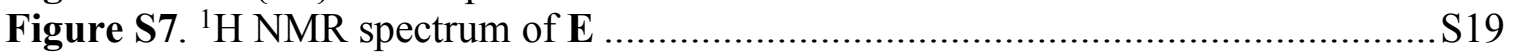

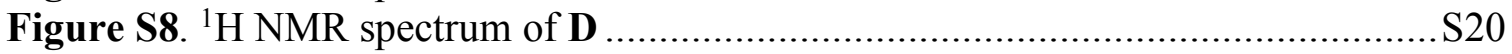

Figure S9. ${ }^{1} \mathrm{H}$ NMR spectrum of representative tetrablock bottlebrush copolymer......S21

Figure S10. ${ }^{19} \mathrm{~F}\left\{{ }^{1} \mathrm{H}\right\}$ NMR spectrum of representative tetrablock bottlebrush

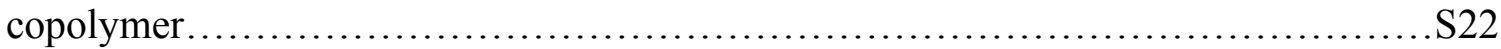

Figure S11. Stacked ${ }^{1} \mathrm{H}$ NMR spectra of tetrablock bottlebrush copolymer after addition

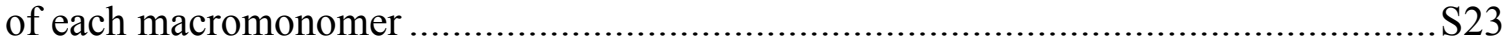

Figure S12. Stacked ${ }^{1} \mathrm{H}$ NMR monitoring the Ru alkylidine proton signals during ROMP S24

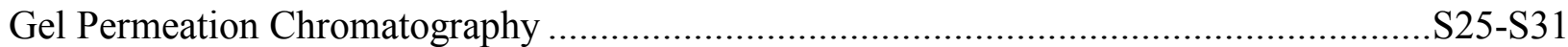

Table S1. Summary of molecular weight and dispersity of homoblock copolymers..... S25

Figure S13. GPC chromatograms of homoblock polymers.....................S25

Figure S14. GPC chromatograms after sequential addition for triblock $\mathbf{S}_{\mathbf{3 0}}-\mathbf{F}_{\mathbf{1 2}}-\mathbf{D}_{\mathbf{2 0}} \ldots \mathrm{S} 26$

Figure S15. GPC chromatograms after sequential addition for triblock $\mathbf{F}_{\mathbf{1 2}}-\mathbf{S}_{\mathbf{3 0}}-\mathbf{D}_{\mathbf{2 0}} \ldots \mathrm{S} 27$

Figure S16. GPC chromatograms after sequential addition for triblock $\mathbf{S}_{\mathbf{3 0}}-\mathbf{D}_{\mathbf{2 0}}-\mathbf{F}_{\mathbf{1 2}} \ldots \mathrm{S} 28$

Figure S17-S22. GPC chromatograms of tetrablock polymers $1-6 \ldots \ldots \ldots \ldots \ldots \ldots . . . . . . . . .29$

Figure S23. GPC chromatograms after sequential addition for polymers $1-5 \ldots \ldots . . \mathrm{S} 30-\mathrm{S} 31$

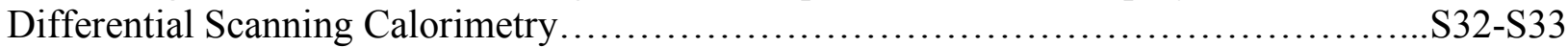

Figure S24. DSC traces of bottle brush polymers to determine block incorporation. .S32-S33

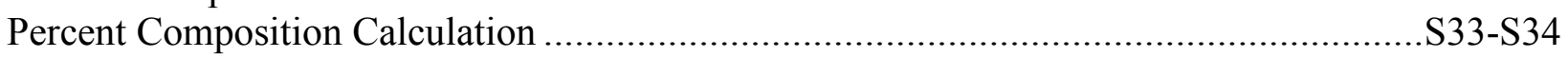


Dynamic Light Scattering Analysis

S34- S37

Micelle Formation Procedure

S34

Table S2. Summary of particle sizes obtained by DLS

S34- S35

Figure S25. DLS traces of bottlebrush polymers from Table S2

$\mathrm{S} 36-\mathrm{S} 37$

Cryogenic Transmission Electron Microscopy....

S38-S42

Figures S26-S38. Cryo-TEM images of Table S2

$\mathrm{S} 38-42$

References S43 
Materials and Methods. All reactions and manipulations of compounds were carried out in air unless otherwise specified. $\mathrm{CDCl}_{3}, \mathrm{CD}_{2} \mathrm{Cl}_{2}$, Acetone- $d_{6}$, DMSO- $d_{6}, \mathrm{CD}_{3} \mathrm{OD}$, and $\mathrm{CD}_{3} \mathrm{OH}$ were all purchased from Cambridge Isotope Laboratories (CIL) and used as received. All reagents and solvents were purchased from commercial sources and used as received unless otherwise specified. Nuclear Magnetic Resonance Spectroscopy (NMR) Analysis. All NMR spectra were recorded on either a 400 or $500 \mathrm{MHz}$ Bruker Advance Spectrometer. The ${ }^{1} \mathrm{H}$ NMR spectra were referenced to residual protio solvents $\left(7.26 \mathrm{ppm}\right.$ for $\mathrm{CHCl}_{3}, 5.32 \mathrm{ppm}$ for $\mathrm{CHDCl}_{2}, 3.31 \mathrm{ppm}$ for $\mathrm{CHD}_{2} \mathrm{OD}$, $3.31 \mathrm{ppm}$ for $\mathrm{CHD}_{2} \mathrm{OH}, 2.50 \mathrm{ppm}$ for DMSO- $d_{5}$, and $2.05 \mathrm{ppm}$ for Acetone- $d_{5}$ ) and ${ }^{13} \mathrm{C}\left\{{ }^{1} \mathrm{H}\right\} \mathrm{NMR}$ were referenced to the solvent signal $\left(\mathrm{CDCl}_{3}: 77.23 \mathrm{ppm}, \mathrm{CD}_{2} \mathrm{Cl}_{2}: 54.00 \mathrm{ppm}\right.$, DMSO- $d_{6}: 39.51$ ppm, and Acetone- $\left.d_{6}: 29.92 \mathrm{ppm}\right)$. The ${ }^{19} \mathrm{~F}\left\{{ }^{1} \mathrm{H}\right\}$ NMR spectra were electronically referenced using internal Bruker software according to a universal scale determined from the precise el ratio, $\Xi$, of the resonance frequency of the ${ }^{19} \mathrm{~F}$ nuclide to the ${ }^{1} \mathrm{H}$ resonance of TMS in a dilute solution $(\varphi<$ $1 \%){ }^{1}$

\section{Gel-Permeation Chromatography (GPC).}

GPC was carried out using a Shimadzu pump coupled to a Shimadzu RI and UV detector, controlled by an EZStart program. A set of polymer standards columns (AM GPC gel, $10 \mu \mathrm{m}$, precolumn, $500 \AA$ and linear mixed bed) was used at a flow rate of $1 \mathrm{ml} / \min$ at $60{ }^{\circ} \mathrm{C}$. The $N, N$ dimethylformamide solution was doped with $0.03 \mathrm{M} \mathrm{LiCl}$. The system was calibrated with poly(styrene) standards (EasiCal, Agilent Technologies, Santa Clara, CA). The injection volume was $100 \mu \mathrm{L}$ and the flow rate was $1 \mathrm{ml} / \mathrm{min}$. The concentrations utilized for GPC measurements are 1-3 $\mathrm{mg} \mathrm{mL}^{-1}$. Mn and dispersity $(\nexists)$ represent the apparent number-average molecular weight and dispersity index respectively. 
Differential Scanning Calorimetry (DSC). Differential scanning calorimetry of the prepared samples was performed on a PerkinElmer DSC 8000 instrument. Thermograms were run in a nitrogen atmosphere, applying heating-cooling-heating runs between -180 and $200{ }^{\circ} \mathrm{C}$ with a rate of $10{ }^{\circ} \mathrm{C} \mathrm{min}-1$. The thermograms of the second heating ramp were analyzed. Temperature and heat flow were calibrated using standard materials (indium and zinc) at cooling and heating rates of $10{ }^{\circ} \mathrm{C} \mathrm{min}^{-1}$.

Dynamic Light Scattering (DLS). DLS was performed on a Malvern Zetasizer Nano using a scattering angle $\theta=173^{\circ}$ (backscattering detection) and a He-Ne laser with a wavelength of 633 $\mathrm{nm}$.

Cryogenic Transmission Electron Microscopy (Cryo-TEM). 400 Mesh holey carbon grids were purchased from Ted Pella and plasma treated for $60 \mathrm{~s}$ using Nanoclean (Fischione) before use. Cryo-TEM grids were prepared in a FEI Vitrobot at $19{ }^{\circ} \mathrm{C}$ with the relative humidity set to $100 \%$ and the blotting force set to $4.3 \mu \mathrm{L}$ of the polymer micelle solution was pipetted onto a freshly glow-discharged grid. The sample solution was incubated on the grid for $10 \mathrm{~s}$, blotted for $2 \mathrm{~s}$ before being plunged into liquid ethane that was pre-cooled by liquid nitrogen. The Cryo-TEM grids were then transferred in liquid nitrogen into a Gatan 626 cryo-specimen holder and then inserted into the microscope. The specimen temperature was maintained at $-170{ }^{\circ} \mathrm{C}$ during data collection. Cryo-TEM imaging was performed in a FEI TITAN Halo TEM operating at $300 \mathrm{kV}$ and recorded in the low dose mode $\left(20 \mathrm{e}^{-} / \AA^{2}\right)$ on a FEI CETA $10 \mathrm{M}$ camera $(4,096 \times 4,096$ pixel $)$. 


\section{Syntheses}

\section{Grubbs' Third Generation Initiator Synthesis}

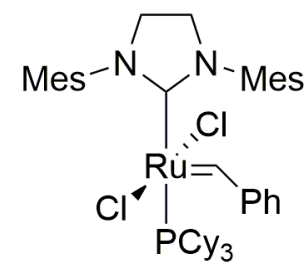

$\underset{\text { toluene, } 22^{\circ} \mathrm{C}, 15 \mathrm{~min}}{\stackrel{100 \text { equiv. pyridine }}{\longrightarrow}}$

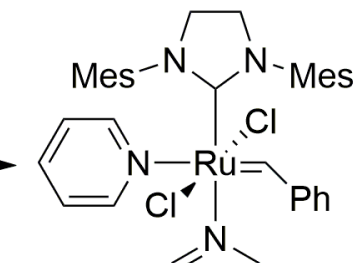

$(1)$

$\left[\left(\mathrm{H}_{2} \mathrm{IMes}\right)(\mathrm{pyr})_{2}(\mathrm{Cl})_{2} \mathrm{Ru}=\mathrm{CHPh}\right]$ was prepared according to a published report. $^{2}$ $\left[\left(\mathrm{H}_{2} \mathrm{IMes}\right)(\mathrm{PCy} 3)(\mathrm{Cl})_{2} \mathrm{Ru}=\mathrm{CHPh}\right](250 \mathrm{mg}, 0.3 \mathrm{mmol})$ was dissolved in $0.5 \mathrm{~mL}$ of anhydrous toluene. Pyridine ( $2.45 \mathrm{~mL}, 30.4 \mathrm{mmol})$ was added and the reaction mixture color rapidly changed from red-brown to dark green. The mixture was stirred for 15 minutes before adding $20 \mathrm{~mL}$ of pentane. The solution was cooled to $0{ }^{\circ} \mathrm{C}$ in a refrigerator and let stand for 17 hours. The precipitate was carefully filtered and the solids were washed with cold pentane $(3 \times 5 \mathrm{~mL})$. The bright green product was dried for 8 hours under vacuum and stored under an inert atmosphere (174 mg, $80 \%$ yield).

\section{ATRP Initiator Syntheses}

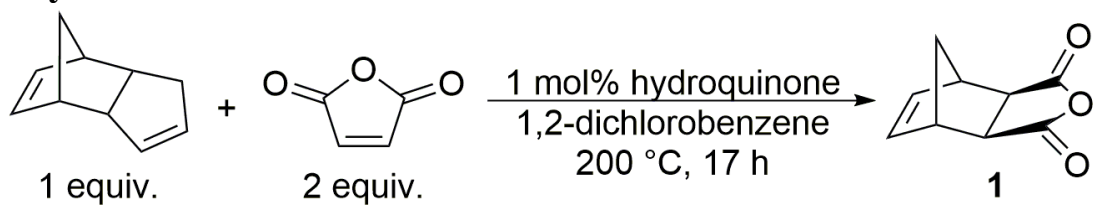

cis-5-Norbornene-exo-2,3-dicarboxylic anhydride, 1, was prepared according to modified literature reports. ${ }^{3-4}$ Dicyclopentadiene $(8.19 \mathrm{~g}, 62.0 \mathrm{mmol})$, maleic anhydride $(11.59 \mathrm{~g}, 118$ $\mathrm{mmol})$, hydroquinone $(65.0 \mathrm{mg}, 0.6 \mathrm{mmol})$, and 1,2-dichlorobenzene $(50 \mathrm{~mL})$ were added to a 250 $\mathrm{mL}$ Ace pressure tube. The contents of the tube were sealed and heated to $200{ }^{\circ} \mathrm{C}$ using an oil bath for 17 hours. The reaction mixture was cooled, and the solvent was removed under vacuum. The solid residue was filtered and washed with cold methanol. The crude product was recrystallized 
from toluene (x5) and ethyl acetate (x2) to give a white, crystalline solid that was dried under vacuum for 6 hours $\left(2.42 \mathrm{~g}, 24 \%\right.$ yield). ${ }^{1} \mathrm{H}$ NMR $\left(400 \mathrm{MHz}, \mathrm{CDCl}_{3}\right) \delta 6.32(\mathrm{t}, J=1.8 \mathrm{~Hz}, 2 \mathrm{H})$, $3.44(\mathrm{t}, J=1.4 \mathrm{~Hz}, 2 \mathrm{H}), 2.99(\mathrm{~d}, J=1.5 \mathrm{~Hz}, 2 \mathrm{H}), 1.75-1.59(\mathrm{~m}, 1 \mathrm{H}), 1.50-1.34(\mathrm{~m}, 1 \mathrm{H}) .{ }^{13} \mathrm{C}\left\{{ }^{1} \mathrm{H}\right\}$ NMR (101 MHz, $\left.\mathrm{CDCl}_{3}\right) \delta 171.8,138.1,48.9,47.0,44.3$.

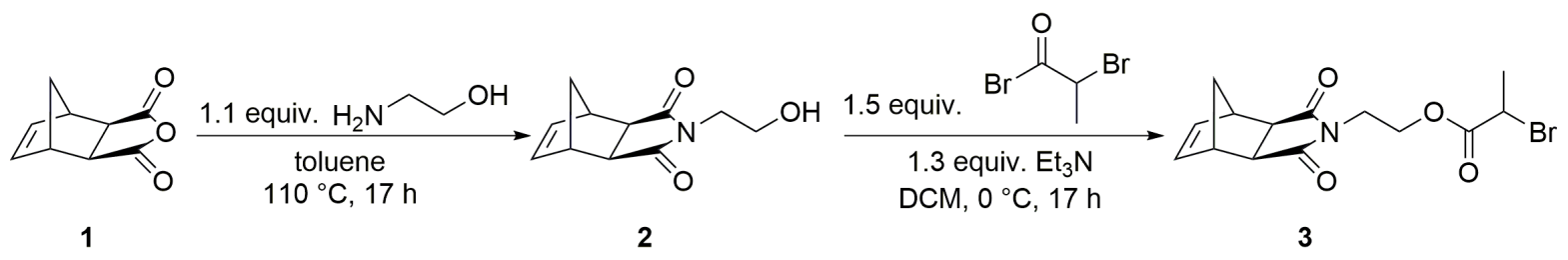

$N$-(2-hydroxyethyl)-cis-5-norbornene-exo-dicarboximide, 2, was prepared according to a modified literature report. ${ }^{5} 1(2.30 \mathrm{~g}, 14.0 \mathrm{mmol})$ and triethylamine $(0.2 \mathrm{~mL}, 1.4 \mathrm{mmol})$ was added to $100 \mathrm{~mL}$ of anhydrous toluene in a $250 \mathrm{~mL}$ round bottomed flask equipped with a reflux condenser and Dean Stark trap. Ethanolamine $(0.91 \mathrm{~mL}, 15.0 \mathrm{mmol})$ was added to the flask and the reaction mixture was heated to reflux for 17 hours using an oil bath. The flask was cooled to $22{ }^{\circ} \mathrm{C}$ and the solvent was removed under vacuum. The residue was diluted with $50 \mathrm{~mL}$ of dichloromethane and was washed with $50 \mathrm{~mL}$ of $10 \%(\mathrm{v} / \mathrm{v}) \mathrm{HCl}, 50 \mathrm{~mL}$ of water, and $50 \mathrm{~mL}$ of brine solution. The organic layer was dried over anhydrous sodium sulfate and then concentrated by rotary evaporation. The resulting solid was collected and dried under vacuum and the product was isolated as a white solid (2.55 g, $88 \%$ yield). ${ }^{1} \mathrm{H}$ NMR (400 MHz, $\left.\mathrm{CDCl}_{3}\right) \delta 6.28(\mathrm{~s}, 2 \mathrm{H}), 3.80$ $-3.73(\mathrm{t}, J=4.9,2 \mathrm{H}), 3.69(\mathrm{t}, J=5.0 \mathrm{~Hz}, 2 \mathrm{H}), 3.28(\mathrm{~s}, 2 \mathrm{H}), 2.71(\mathrm{~s}, 2 \mathrm{H}), 2.13(\mathrm{~s}, 1 \mathrm{H}), 1.51(\mathrm{~d}, J$ $=9.9,1 \mathrm{H}), 1.34(\mathrm{~d}, J=9.9 \mathrm{~Hz}, 1 \mathrm{H}) \cdot{ }^{13} \mathrm{C}\left\{{ }^{1} \mathrm{H}\right\} \mathrm{NMR}\left(100 \mathrm{MHz}, \mathrm{CDCl}_{3}\right) \delta 178.0,138.0,60.5,48.1$, $45.5,43.1,39.9$.

$N$-(2-bromopropanoylethyl)-exo,cis-2,3-dicarboximide, 3, was prepared according to a modified literature report. ${ }^{6} \mathbf{2}(1.45 \mathrm{~g}, 7.0 \mathrm{mmol})$ and triethylamine $(1.3 \mathrm{~mL}, 9.3 \mathrm{mmol})$ were added 
to anhydrous dichloromethane $(100 \mathrm{~mL})$ in a $250 \mathrm{~mL}$ round bottomed flask equipped with an addition funnel. The contents of the flask were cooled to $0{ }^{\circ} \mathrm{C}$ and the addition funnel was charged with $75 \mathrm{~mL}$ of anhydrous dichloromethane and 2-bromopropionyl bromide (1.2 mL, $11.4 \mathrm{mmol})$. The 2-bromopropionyl bromide solution was added dropwise to the reaction vessel and, after full addition, the reaction mixture was warmed to $22{ }^{\circ} \mathrm{C}$ and stirred for 17 hours. The reaction mixture was then transferred to a separatory funnel where it was washed with $10 \% \mathrm{v} / \mathrm{v} \mathrm{HCl}$ solution $(3 \times$ $100 \mathrm{~mL})$, saturated $\mathrm{NaHCO}_{3}$ solution $(3 \times 100 \mathrm{~mL})$, once $100 \mathrm{~mL}$ of deionized water, and once with $100 \mathrm{~mL}$ of saturated $\mathrm{NaCl}$ solution. The organic layer was dried over anhydrous sodium sulfate and concentrated by rotary evaporation. The crude yellow oil was further purified by column chromatography using silica and 2:1 v/v ethyl acetate/hexanes cosolvent as the eluent. The resulting oil was placed under high vacuum and heated to $50{ }^{\circ} \mathrm{C}$ for 10 hours to remove residual solvent and the product was obtained as a highly viscous colorless oil $(1.72 \mathrm{~g}, 72 \%$ yield $) .{ }^{1} \mathrm{H}$ NMR (400 MHz, $\left.\mathrm{CDCl}_{3}\right) \delta 6.29(\mathrm{t}, J=1.9 \mathrm{~Hz}, 2 \mathrm{H}), 4.42-4.34(\mathrm{~m}, 1 \mathrm{H}), 4.34-4.25(\mathrm{~m}, 2 \mathrm{H}), 3.89$ $-3.71(\mathrm{~m}, 2 \mathrm{H}), 3.28(\mathrm{t}, J=1.7 \mathrm{~Hz}, 2 \mathrm{H}), 2.71(\mathrm{~d}, J=1.4 \mathrm{~Hz}, 2 \mathrm{H}), 1.80(\mathrm{~d}, J=7.0 \mathrm{~Hz}, 3 \mathrm{H}), 1.53$ (d, 1H), $1.31(\mathrm{~d}, 1 \mathrm{H}) .{ }^{13} \mathrm{C}\left\{{ }^{1} \mathrm{H}\right\} \mathrm{NMR}\left(100 \mathrm{MHz}, \mathrm{CDCl}_{3}\right) \delta$ 178.0, 170.1, 138.0, 62.5, 48.1, 45.5, 43.1, 39.9, 37.5, 21.7. HRMS (APCI): $\mathrm{m} / \mathrm{z}$ calculated for $\mathrm{C}_{14} \mathrm{H}_{31} \mathrm{BrNO}_{4}\left(\mathrm{M}^{+}\right)=341.03$; found $[\mathrm{M}+\mathrm{H}]^{+}=342.03$

\section{Macromonomer Syntheses}

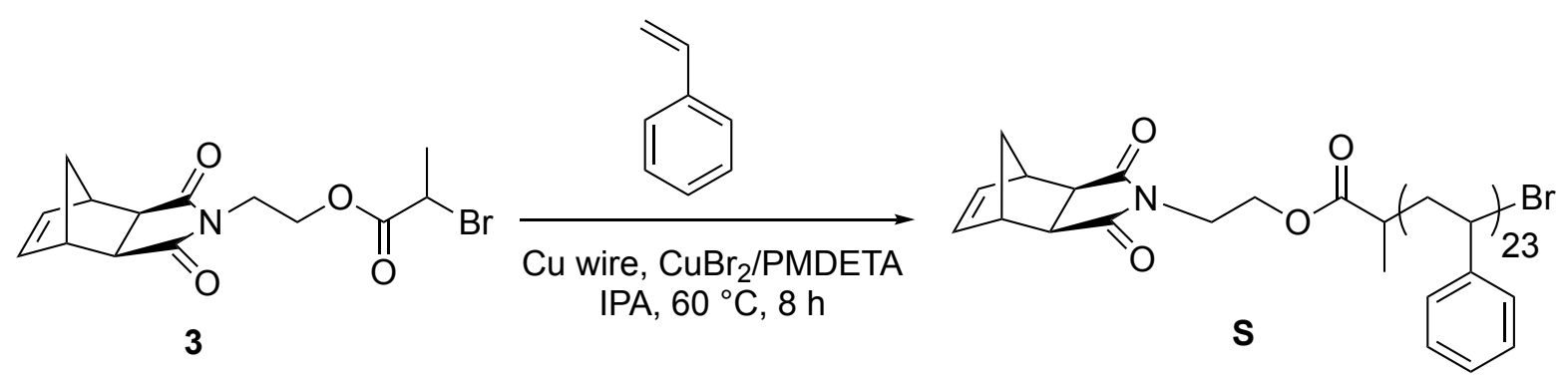


Representative S macromonomer synthesis by $\mathbf{C u ( 0 )}$ mediated ATRP. In a $15 \mathrm{~mL}$ Schlenk Flask, styrene (5 mL, $43.6 \mathrm{mmol}), N, N, N^{\prime}, N^{\prime \prime}, N$ "'-pentamethyldiethylenetriamine (PMDETA) ( $76.0 \mu \mathrm{L}, 0.37 \mathrm{mmol})$, copper wire $(3 \mathrm{~cm}), \mathrm{CuBr}_{2}(8.0 \mathrm{mg}, 36.6 \mu \mathrm{mol})$ were added to $3.0 \mathrm{~mL}$ of isopropyl alcohol and degassed for 30 minutes using argon. The initiator solution was prepared in a separate $5 \mathrm{~mL}$ Schlenk flask by dissolving $3(0.25 \mathrm{~g}, 0.73 \mathrm{mmol})$ in $2.0 \mathrm{~mL}$ of isopropyl alcohol and this solution was degassed for 30 minutes using argon. After both solutions were thoroughly degassed, the initiator solution was injected into the first solution and the reaction mixture was placed in an oil bath pre-heated to $60^{\circ} \mathrm{C}$. The polymerization was stopped after 8 hours by opening the contents of the flask to the atmosphere. The reaction mixture was precipitated into $200 \mathrm{~mL}$ of methanol and the blue solids were collected using vacuum filtration. Residual copper was removed by dissolving the polymers in $20 \mathrm{~mL}$ of acetone and passing it through a column of alumina. The polymer was further purified by dialysis against acetone using a $1 \mathrm{kD}$ dialysis bag. The polymers were isolated as a white solid by precipitation into $100 \mathrm{~mL}$ of methanol and collection using vacuum filtration.

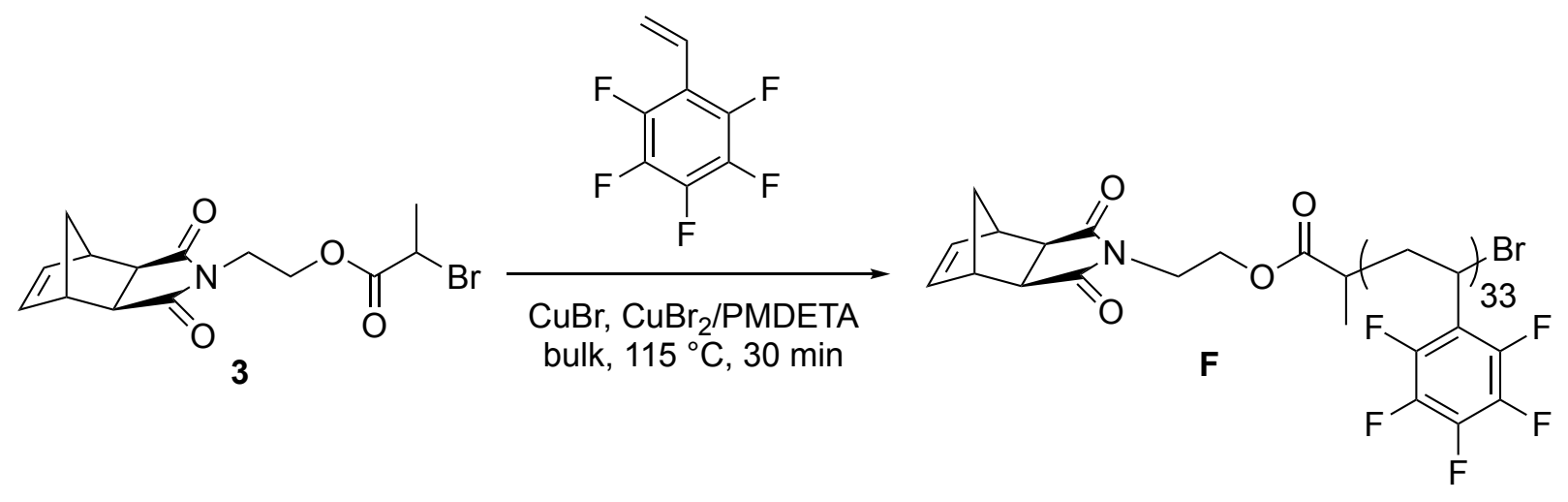

Representative F macromonomer synthesis by ATRP. In a $15 \mathrm{~mL}$ Schlenk flask, 2,3,4,5,6 pentafluorostyrene $(3.0 \mathrm{~mL}, 21.7 \mathrm{mmol}), N, N, N^{\prime}, N^{\prime \prime}, N$ " pentamethyldiethylenetriamine (PMDETA) $(18.0 \mu \mathrm{L}, 86.9 \mu \mathrm{mol}), \mathrm{CuBr}(12.5 \mathrm{mg}, 86.9 \mu \mathrm{mol}), \mathrm{CuBr}_{2}(5.0 \mathrm{mg}, 21.7 \mu \mathrm{mol})$ were added and degassed for 30 minutes using argon. The initiator solution was prepared by dissolving 
3 (149 mg, $0.29 \mathrm{mmol}$ ) in $1.0 \mathrm{~mL}$ of 2,3,4,5,6-pentafluorostyrene and this solution was degassed using argon for 30 minutes. After both solutions were thoroughly degassed, the initiator solution was injected into the first solution and the reaction mixture was placed in an oil bath pre-heated to $115^{\circ} \mathrm{C}$. The polymerization was stopped after 30 minutes by opening the contents of the flask to the atmosphere. The reaction mixture was precipitated into $100 \mathrm{~mL}$ of methanol and the blue solids were collected using vacuum filtration. Residual copper was removed by dissolving the polymers in $20 \mathrm{~mL}$ of acetone and passing it through a column of alumina. The polymer was further purified by dialysis against acetone in a $5 \mathrm{kD}$ dialysis bag. The polymers were isolated as a white solid by precipitation into $100 \mathrm{~mL}$ of methanol and collection using vacuum filtration.

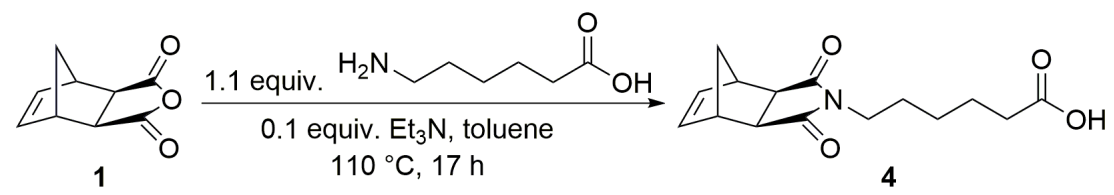

Norbornene carboxylic acid imide, 4, was prepared according to a published report. ${ }^{7} \mathbf{1}$ (1.50 g, $9.1 \mathrm{mmol})$ and triethylamine $(0.12 \mathrm{~mL}, 0.9 \mathrm{mmol})$ were added to a $100 \mathrm{~mL}$ round bottomed flask containing $46 \mathrm{~mL}$ of toluene. 6-Aminohexanoic acid $(1.20 \mathrm{~g}, 9.1 \mathrm{mmol})$ was added in portions to the reaction mixture. A reflux condenser was attached and the contents of the flask were heated to $110^{\circ} \mathrm{C}$ using an oil bath. The mixture was stirred for 17 hours and then was cooled to $22{ }^{\circ} \mathrm{C}$. After removal of the solvent by rotary evaporation, the crude oil was diluted with $50 \mathrm{~mL}$ of dichloromethane and transferred to a separatory funnel. The organic layer was washed with 10\% $\mathrm{v} / \mathrm{v} \mathrm{HCl}$ solution $(2 \times 40 \mathrm{~mL})$, deionized water $(2 \times 40 \mathrm{~mL})$, and once with saturated $\mathrm{NaCl}$ solution $(40 \mathrm{~mL})$. The organic layer was dried over anhydrous sodium sulfate and concentrated using rotary evaporation. The residue was purified by column chromatography using a plug of silica. The plug was initially flushed with $200 \mathrm{~mL}$ of dichloromethane and then with acetone and fractions were 
collected. After removal of the solvent, the product was obtained as a waxy, white solid (1.92 g, $76 \%$ yield). ${ }^{1} \mathrm{H}$ NMR (400 MHz, $\left.\mathrm{CDCl}_{3}\right) \delta 6.27$ (t, $\left.J=1.9 \mathrm{~Hz}, 2 \mathrm{H}\right), 3.51-3.41(\mathrm{~m}, 2 \mathrm{H}), 3.26(\mathrm{t}$, $J=1.7 \mathrm{~Hz}, 2 \mathrm{H}), 2.67(\mathrm{~d}, J=1.3 \mathrm{~Hz}, 2 \mathrm{H}), 2.33(\mathrm{t}, J=7.4 \mathrm{~Hz}, 2 \mathrm{H}), 1.72-1.45(\mathrm{~m}, 5 \mathrm{H}), 1.41-1.27$ (m, 2H), $1.20(\mathrm{~d}, J=9.3,1.6,1 \mathrm{H}) .{ }^{13} \mathrm{C}\left\{{ }^{1} \mathrm{H}\right\} \mathrm{NMR}\left(100 \mathrm{MHz}, \mathrm{CDCl}_{3}\right) \delta$ 178.9, 178.0, 138.0, 47.9, $45.3,42.8,38.5,33.8,27.5,26.5,24.3$.

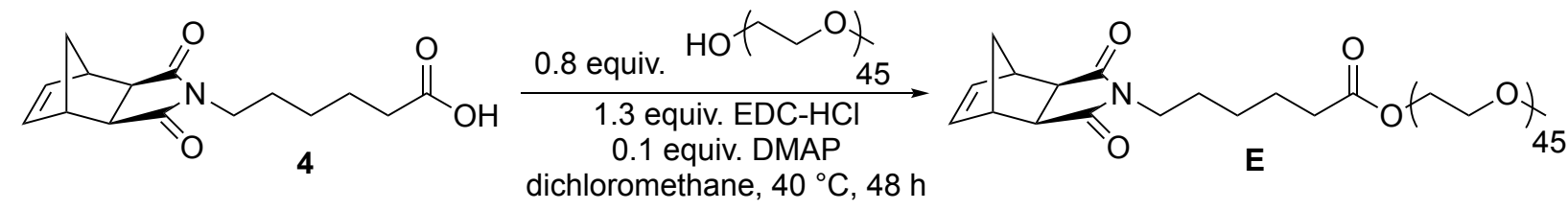

E macromonomer. The $\mathbf{E}$ macromonomer was prepared according to a published report. ${ }^{7} \mathrm{~A}$ representative example is given using monohydroxy $\mathrm{PEG}_{2000} 4$ (0.83 g, $\left.3.0 \mathrm{mmol}\right), \mathrm{PEG}_{2000}$ (5.0 g, $2.5 \mathrm{mmol}$ ), and 4-dimethylamino pyridine (DMAP) $30.5 \mathrm{mg}, 0.25 \mathrm{mmol}$ ) were dissolved in 25 $\mathrm{mL}$ of anhydrous dichloromethane. $\quad N$-(3-dimethylaminopropyl)- $N^{\prime}$-ethylcarbodiimide hydrochloride $(\mathrm{EDC}-\mathrm{HCl})(0.77 \mathrm{~g}, 4.0 \mathrm{mmol})$ was added and the reaction mixture was heated to $40{ }^{\circ} \mathrm{C}$ using an oil bath. The mixture was stirred for 48 hours. After cooling to $22{ }^{\circ} \mathrm{C}$, the reaction mixture was transferred to a separatory funnel, diluted with $20 \mathrm{~mL}$ of dichloromethane and washed with $1 \mathrm{M} \mathrm{HCl}$ solution $(3 \times 30 \mathrm{~mL})$ and saturated $\mathrm{NaCl}$ solution $(2 \times 20 \mathrm{~mL})$. The organic layer was dried over anhydrous sodium sulfate and concentrated to approximately $5 \mathrm{~mL}$. The product was obtained by precipitating the crude oil into cold diethyl ether and filtering the solids. The solids were fully dried under high vacuum at $75{ }^{\circ} \mathrm{C}$ for 8 hours $(4.9 \mathrm{~g}, 86 \%$ yield). The complete coupling of PEG with the norbornene carboxylic acid imide was confirmed through GPC analysis. 


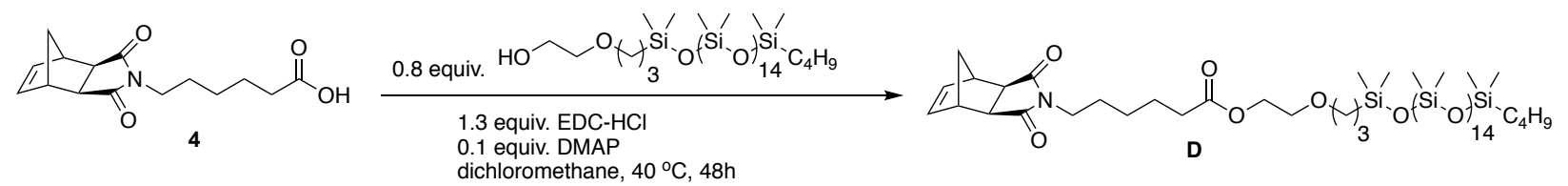

D macromonomer. The $\mathbf{D}$ macromonomer was prepared according to a published report. ${ }^{8} 4(0.17$ g, $0.6 \mathrm{mmol}), \mathrm{PDMS}_{1000}(0.50 \mathrm{~g}, 0.5 \mathrm{mmol})$, and 4-dimethylamino pyridine (DMAP) $(6.11 \mathrm{mg}$, $0.05 \mathrm{mmol}$ ) were dissolved in $5.0 \mathrm{~mL}$ of anhydrous dichloromethane. $N$-(3-dimethylaminopropyl)$N^{\prime}$-ethylcarbodiimide hydrochloride $(\mathrm{EDC}-\mathrm{HCl})(0.153 \mathrm{~g}, 0.8 \mathrm{mmol})$ was added and the reaction mixture was stirred for 48 hours at $40{ }^{\circ} \mathrm{C}$ in an oil bath. The mixture was transferred to a separatory funnel and washed with $1 \mathrm{M} \mathrm{HCl}$ solution $(3 \times 30 \mathrm{~mL})$, deionized water $(3 \times 30 \mathrm{~mL})$ and saturated $\mathrm{NaCl}$ solution $(2 \times 20 \mathrm{~mL})$. The organic layer was dried over anhydrous sodium sulfate and the residue was filtered through a plug of silica with dichloromethane $(500 \mathrm{~mL})$. The solvent was removed by rotary evaporation and the polymer was further dried under high vacuum at $75{ }^{\circ} \mathrm{C}$ for 8 hours and a viscous oil was obtained $(0.44 \mathrm{~g}, 70 \%$ yield $)$.

\section{General ROMP Polymerization Procedure}

\section{Tetrablock}

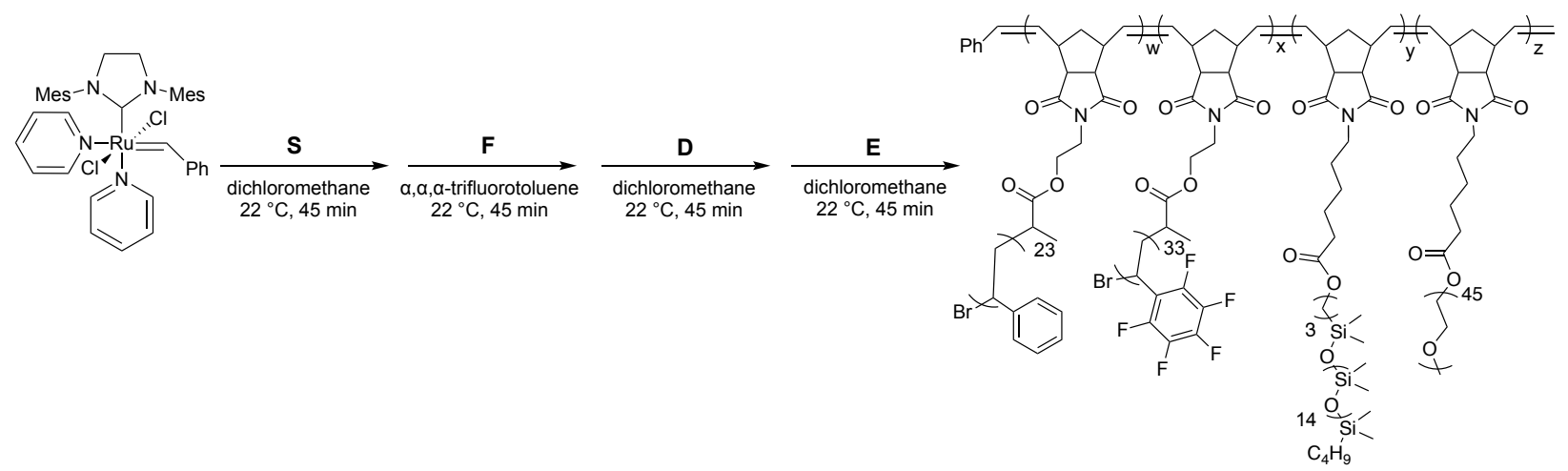

Ring-Opening Metathesis Polymerization to form a tetrablock bottlebrush copolymer was conducted in a dry glovebox under a $\mathrm{N}_{2}$ atmosphere. A $10 \mathrm{mg} / \mathrm{mL}$ stock solution of G3 in dry dichloromethane was prepared and a $50 \mu \mathrm{L}$ aliquot of the initiator solution was added to a $20 \mathrm{~mL}$ 
scintillation vial. Stock solutions for $\mathbf{E}, \mathbf{S}$, and $\mathbf{D}$ were prepared by dissolving the determined amount of monomer in dry dichloromethane so that the final concentration was $0.02 \mathrm{M}$. A stock solution of $\mathbf{F}$ was prepared by dissolving the determined amount of monomer in dry, distilled $\alpha, \alpha, \alpha$, -trifluorotoluene so that the final concentration was $0.05 \mathrm{M}$. Polymerization was initiated by injecting the calculated amount of monomer solution into the catalyst solution under vigorous stirring at $22{ }^{\circ} \mathrm{C}$. The color of the catalyst solution quickly turned from green to light brown. After 45 minutes, a second addition of monomer was injected into the reaction mixture. This was repeated for the third monomer addition. After a final 45 minutes (180 minutes total polymerization time), $0.1 \mathrm{~mL}$ of ethyl vinyl ether was added to quench the polymerization and the reaction mixture was stirred for 15 minutes. The solvent was removed by rotary evaporation and the crude polymer was purified by dialysis against acetone. The contents of the dialysis bag were transferred to a pre-weighed $20 \mathrm{~mL}$ scintillation vial and the solvent was removed by rotary evaporation. The remaining solid was further dried under in vacuo on a Schlenk line (50 mtorr) at $50{ }^{\circ} \mathrm{C}$ for 4 hours.

\section{Representative Ring-Opening Metathesis Polymerization}

The initiator stock solution was prepared by dissolving $1.5 \mathrm{mg}$ of $\mathbf{G 3}$ in $0.15 \mathrm{~mL}$ of dry dichloromethane. $50 \mu \mathrm{L}(0.5 \mathrm{mg}, 0.69 \mu \mathrm{mol})$ of the $\mathbf{G} 3$ initiator stock solution was added to a 20 $\mathrm{mL}$ scintillation vial. In four separate vials, $100 \mathrm{mg}(0.043 \mathrm{mmol})$ of $\mathbf{E}$ was dissolved in $1.5 \mathrm{~mL}$ of dry dichloromethane, $63 \mathrm{mg}(0.022 \mathrm{mmol})$ of $\mathbf{S}$ was dissolved in $1.3 \mathrm{~mL}$ of dry dichloromethane, $19 \mathrm{mg}(0.014 \mathrm{mmol})$ of $\mathbf{D}$ was dissolved in $1.2 \mathrm{~mL}$ of dry dichloromethane and $57 \mathrm{mg}(0.0087$ $\mathrm{mmol}$ ) of $\mathbf{F}$ was dissolved in $0.17 \mathrm{~mL}$ of $\alpha, \alpha, \alpha$, ,trifluorotoluene. The monomer solution containing S was injected into the catalyst solution at $22{ }^{\circ} \mathrm{C}$ and was vigorously stirred for 45 minutes. The monomer solution containing $\mathbf{F}$ was then injected and the polymerization was stirred for another 
45 minutes. Next, the $\mathbf{D}$ monomer solution was added, and the reaction was stirred for an additional 45 minutes. After a final injection of the monomer solution containing $\mathbf{E}$, the polymerization was stirred for 45 minutes and then 0.1 of ethyl vinyl ether was added. The reaction mixture was stirred for 15 minutes after which it was purified by dialysis against acetone. The product was obtained as a white solid (146 $\mathrm{mg}, 61 \%$ yield).

\section{ROMP Livingness Experiments}

A chain extension experiment was performed to confirm full chain-end fidelity during multiblock copolymerization. In a dry glovebox under $\mathrm{N}_{2}$ atmosphere, a stock solution of $\mathbf{G} 3$ was prepared by weighing out $\mathbf{G 3}(1.0 \mathrm{mg}, 1.45 \mu \mathrm{mol})$ in a $20 \mathrm{~mL}$ scintillation vial and dissolving it in $0.2 \mathrm{~mL}$ of dry dichloromethane. $75 \mu \mathrm{L}(0.54 \mu \mathrm{mol})$ of the $\mathbf{G} 3$ stock solution was taken out and added to another $20 \mathrm{~mL}$ vial equipped with a stir bar. In a $4 \mathrm{~mL}$ vial, $\mathbf{E}(125 \mathrm{mg}, 5.43 \mathrm{mmol})$ was dissolved in $2.7 \mathrm{~mL}$ of dry dichloromethane and the solution was injected into the vial containing the G3. After 45 minutes, $100 \mu \mathrm{L}$ aliquot was removed, the polymerization was terminated by adding 50 $\mu \mathrm{L}$ of ethyl vinyl ether and dried under vacuo. The solution was diluted with $0.6 \mathrm{~mL}$ of $\mathrm{CDCl}_{3}$ for ${ }^{1} \mathrm{H}$ NMR analysis. In another vial, $\mathbf{S}(152 \mathrm{mg}, 5.43 \mathrm{mmol})$ was dissolved in $2.7 \mathrm{~mL}$ dry dichloromethane and this solution was injected into the polymerization mixture. After 45 minutes, another $100 \mu \mathrm{L}$ aliquot was removed. The polymerization was terminated by adding $50 \mu \mathrm{L}$ of ethyl vinyl ether and dried and diluted with $0.6 \mathrm{~mL}$ of $\mathrm{CDCl}_{3}$ for ${ }^{1} \mathrm{H} \mathrm{NMR}$ analysis. In a separate $4 \mathrm{~mL}$ vial, F (270 mg, $5.43 \mathrm{mmol}$ ) was dissolved in $1.1 \mathrm{~mL}$ of $\alpha, \alpha, \alpha$,-trifluorotoluene and this solution was injected into the polymerization mixture. After 45 minutes, a $100 \mu \mathrm{L}$ aliquot was removed, the polymerization was terminated by $50 \mu \mathrm{L}$ of ethyl vinyl ether and diluted with $0.6 \mathrm{~mL}$ of $\mathrm{CDCl}_{3}$

for ${ }^{1} \mathrm{H}$ NMR analysis. In a final $4 \mathrm{~mL}$ vial, $\mathbf{D}(71 \mathrm{mg}, 5.43 \mathrm{mmol})$ was dissolved in $2.7 \mathrm{~mL}$ of dry dichloromethane and this solution was injected into the polymerization mixture. After 45 minutes, 
a $100 \mu \mathrm{L}$ aliquot was removed, the polymerization was terminated by $50 \mu \mathrm{L}$ of ethyl vinyl ether and diluted with $0.6 \mathrm{~mL}$ of $\mathrm{CDCl}_{3}$ for ${ }^{1} \mathrm{H}$ NMR analysis. The disappearance of the norbornyl macromonomer signals $\delta(6.31-6.26 \mathrm{ppm})$ after each addition was observed as expected and an increase in signals corresponding to internal vinyl protons along the bottlebrush backbone $\delta$ (6.0 5.31) was observed (Figure S11).

Chain end fidelity was further confirmed by the GPC analysis of triblock copolymers after the subsequent addition of each macromonomer. In a glovebox under $\mathrm{N}_{2}$ atmosphere, $\mathbf{G} 3$ ( $0.5 \mathrm{mg}$, $0.72 \mu \mathrm{mol}$ ) was added to a $20 \mathrm{~mL}$ vial equipped with a stir bar and dissolved in $0.1 \mathrm{~mL}$ DCM. In a $4 \mathrm{~mL}$ vial, $\mathbf{S}(61 \mathrm{mg}, 21.7 \mu \mathrm{mol})$ was dissolved in $2.1 \mathrm{~mL}$ of dry dichloromethane and the solution was injected into the vial containing the G3. After 45 minutes, $100 \mu \mathrm{L}$ aliquot was removed, the polymerization was terminated by adding $50 \mu \mathrm{L}$ of ethyl vinyl ether and dried under vacuo. The solution was diluted with $1.0 \mathrm{~mL}$ of THF for GPC analysis. In a third vial, F (43.5 mg, $8.7 \mu \mathrm{mol})$ was dissolved in $0.9 \mathrm{~mL}$ of $\alpha, \alpha, \alpha$, -trifluorotoluene and this solution was injected into the polymerization mixture. After 45 minutes, another $100 \mu \mathrm{L}$ aliquot was removed. The polymerization was terminated by adding $50 \mu \mathrm{L}$ of ethyl vinyl ether and dried and diluted with 1.0 $\mathrm{mL}$ of THF for GPC analysis. In a separate $4 \mathrm{~mL}$ vial, D $(19.0 \mathrm{mg}, 14.5 \mu \mathrm{mol})$ was dissolved in $1.5 \mathrm{~mL}$ dry dichloromethane and this solution was injected into the polymerization mixture. After 45 minutes, a $100 \mu \mathrm{L}$ aliquot was removed, the polymerization was terminated by $50 \mu \mathrm{L}$ of ethyl vinyl ether and diluted with $1.0 \mathrm{~mL}$ of THF for GPC analysis. For each GPC curve, complete consumption of macromonomer is observed along with unimodal peaks indicating low molar mass dispersity (Figure S14). The same procedure was repeated to synthesize triblock copolymers with two other block orders by changing the order or addition (Figure S15 and S16). 
ROMP livingness was also investigated by monitoring the Ru alkylidene proton signal over time. In a glovebox under $\mathrm{N}_{2}$ atmosphere, $\mathbf{G 3}(2.5 \mathrm{mg}, 3.4 \mu \mathrm{mol})$ was added to an NMR tube and dissolved in $0.5 \mathrm{~mL}$ of $\mathrm{CDCl}_{3}$. The tube was capped and an initial ${ }^{1} \mathrm{H}$ NMR spectrum was collected. In a separate vial, $(143 \mathrm{mg}, 51 \mu \mathrm{mol})$ of $\mathbf{S}$ was dissolved in $0.5 \mathrm{~mL}$ of $\mathrm{CDCl}_{3}$. The cap of the NMR tube was briefly removed (resulting in some air exposure) and the macromonomer solution was rapidly injected. The tube was inverted several times to thoroughly mix the solution. NMR spectra were collected after 11, 21, and 42 minutes. After 11 minutes of polymerization time, the alkylidine proton signal corresponding to $\mathbf{G 3} \delta(19.21 \mathrm{ppm})$ broadened and shifted to $\delta 18.81-18.57 \mathrm{ppm}$. The integral of this region was compared to the integral between $\delta 7.51-6.37 \mathrm{ppm}$ (aromatic styrenyl protons) (Figure S12). A small percentage (3-6\%) of unreacted G3 was observed throughout the entire polymerization time.

\section{ROMP Kinetic Experiments}

In a glovebox under $\mathrm{N}_{2}$ atmosphere, $\mathbf{G 3}(0.5 \mathrm{mg}, 0.72 \mu \mathrm{mol})$ was weighed out in a $20 \mathrm{~mL}$ vial and dissolved in either $\mathrm{CD}_{2} \mathrm{Cl}_{2}$ or $\mathrm{CDCl}_{3}(0.1 \mathrm{~mL})$. Macromonomer $(10.9 \mu \mathrm{mol})$ was weighed out in a separate vial, dissolved in either $\mathrm{CD}_{2} \mathrm{Cl}_{2}$ or $\mathrm{CDCl}_{3}(0.01 \mathrm{M})$ and added to a J. Young valve NMR tube. An initial ${ }^{1} \mathrm{H}$ NMR spectrum was collected of the macromonomer following the rapid addition of G3 into the NMR tube. The tube was inverted several times to thoroughly mix the solution and a stopwatch was started to accurately time the kinetics. NMR spectra were collected at 60 seconds intervals for 45 minutes. The integral of the norbornene vinyl proton signal at $\delta 6.34$ ppm was compared to the bottlebrush backbone between $\delta 5.31-6.00 \mathrm{ppm}$ to determine the percentage conversion of the macromonomer to the bottlebrush. The ${ }^{1} \mathrm{H}$ NMR spectra were used to plot $\ln \left(\left[\mathrm{M}_{\mathrm{o}}\right] /\left[\mathrm{M}_{\mathrm{t}}\right]\right)$ versus time graphs (Figure $\mathrm{S} 1$ ). All macromonomers polymerized within 16 minutes. 


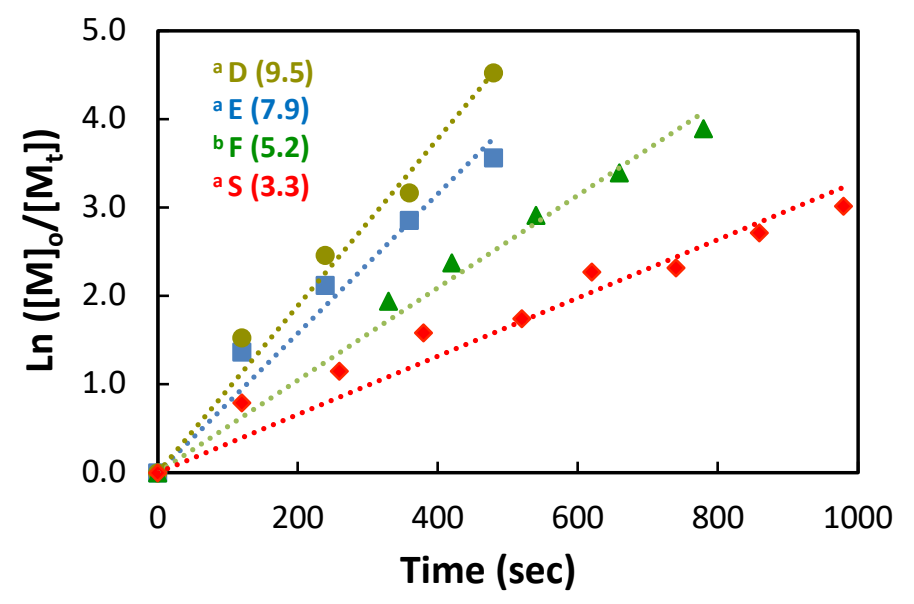

Figure S1. Plots of $\ln \left(\left[\mathrm{M}_{\mathrm{o}}\right] /\left[\mathrm{M}_{\mathrm{t}}\right]\right)$ versus time, showing first-order kinetics for the homopolymerization of norbornene monomers $(0.01 \mathrm{M})$ catalyzed by $\mathbf{G 3}(1.5 \mathrm{mM})$ in a) $\mathrm{CH}_{2} \mathrm{Cl}_{2}$, b) $\mathrm{CHCl}_{3}$ at $298 \mathrm{~K}$ (golden dots, $\mathbf{D}$; blue squares, $\mathbf{E}$; green triangles, $\mathbf{F}$; red diamonds, $\mathbf{S}$ ). The numbers in parentheses represent the values of $\mathrm{k}_{\mathrm{obs}}\left(10^{-3} \mathrm{~s}^{-1}\right)$ under these conditions. Polymerization was complete for all four blocks within 1000 seconds. 


\section{NMR Spectra}

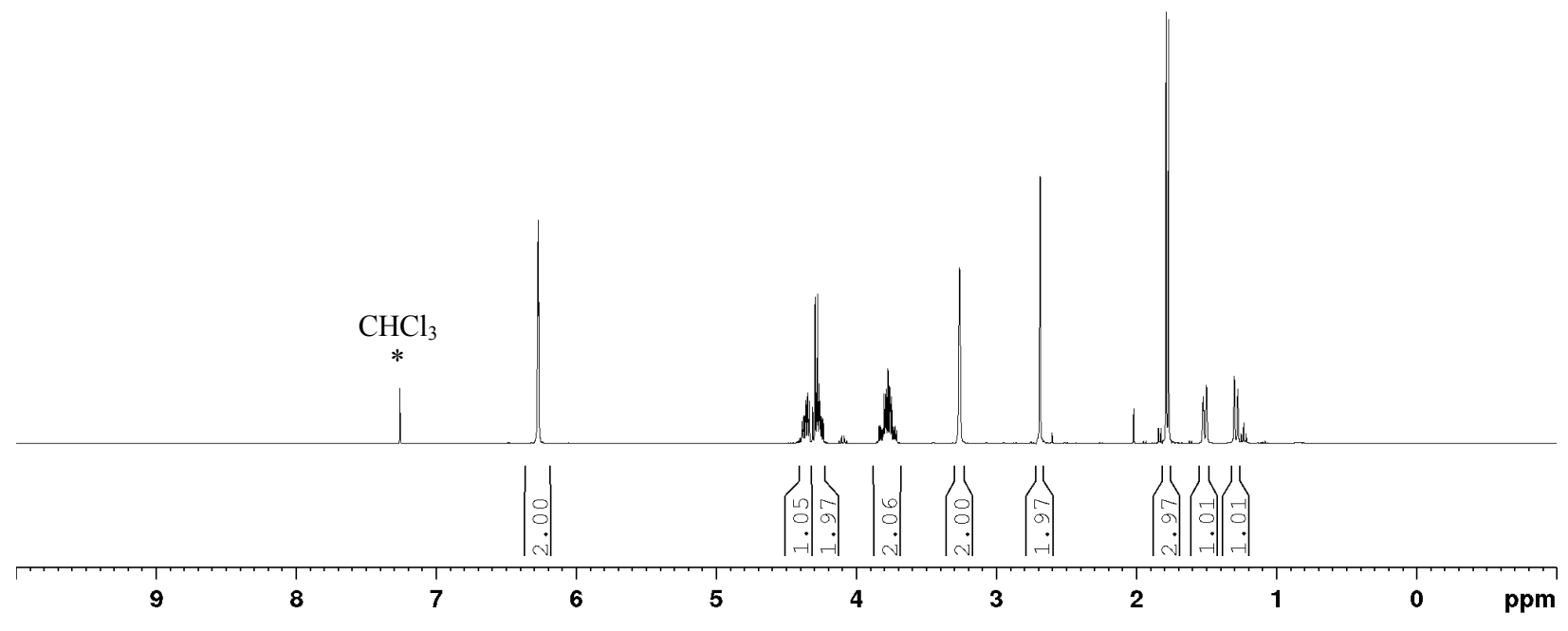

Figure S2. ${ }^{1} \mathrm{H}$ NMR spectrum of ATRP initiator 3. $\mathrm{CDCl}_{3}, 400 \mathrm{MHz}$.

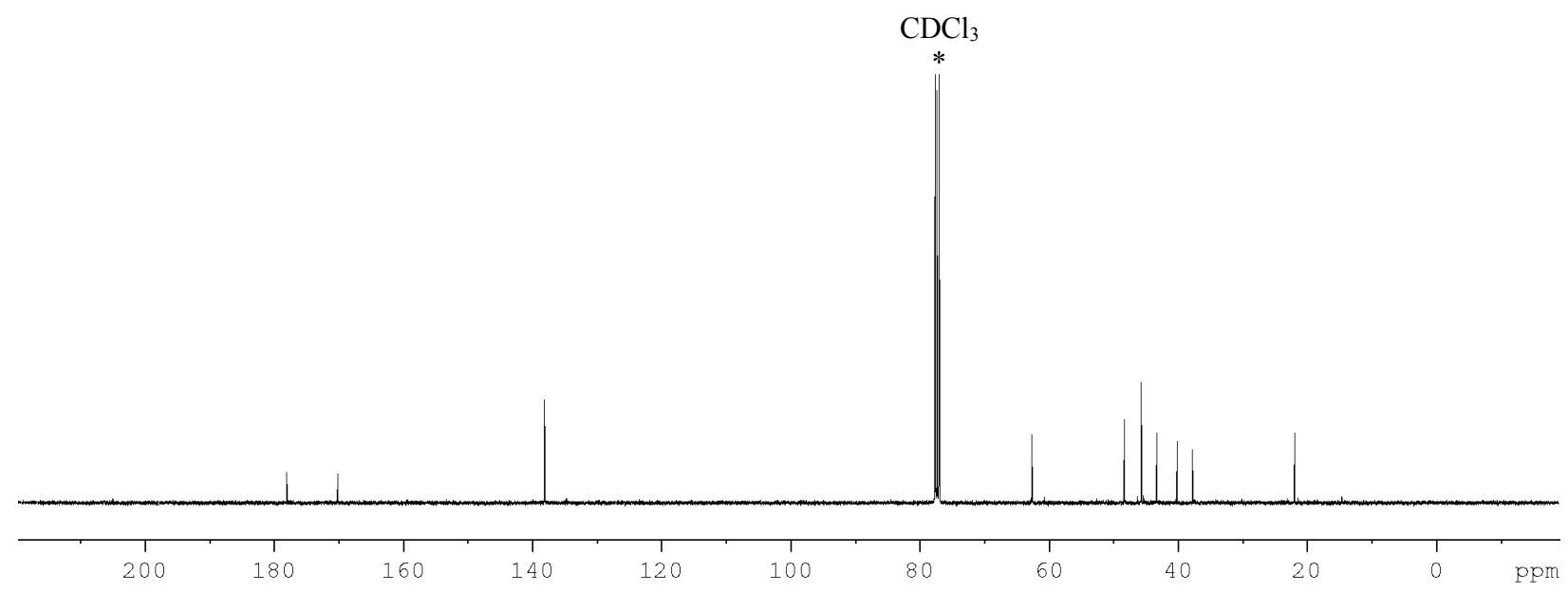

Figure S3. ${ }^{13} \mathrm{C}\left\{{ }^{1} \mathrm{H}\right\}$ NMR spectrum of the ATRP initiator 3. $\mathrm{CDCl}_{3}, 100 \mathrm{MHz}$. 


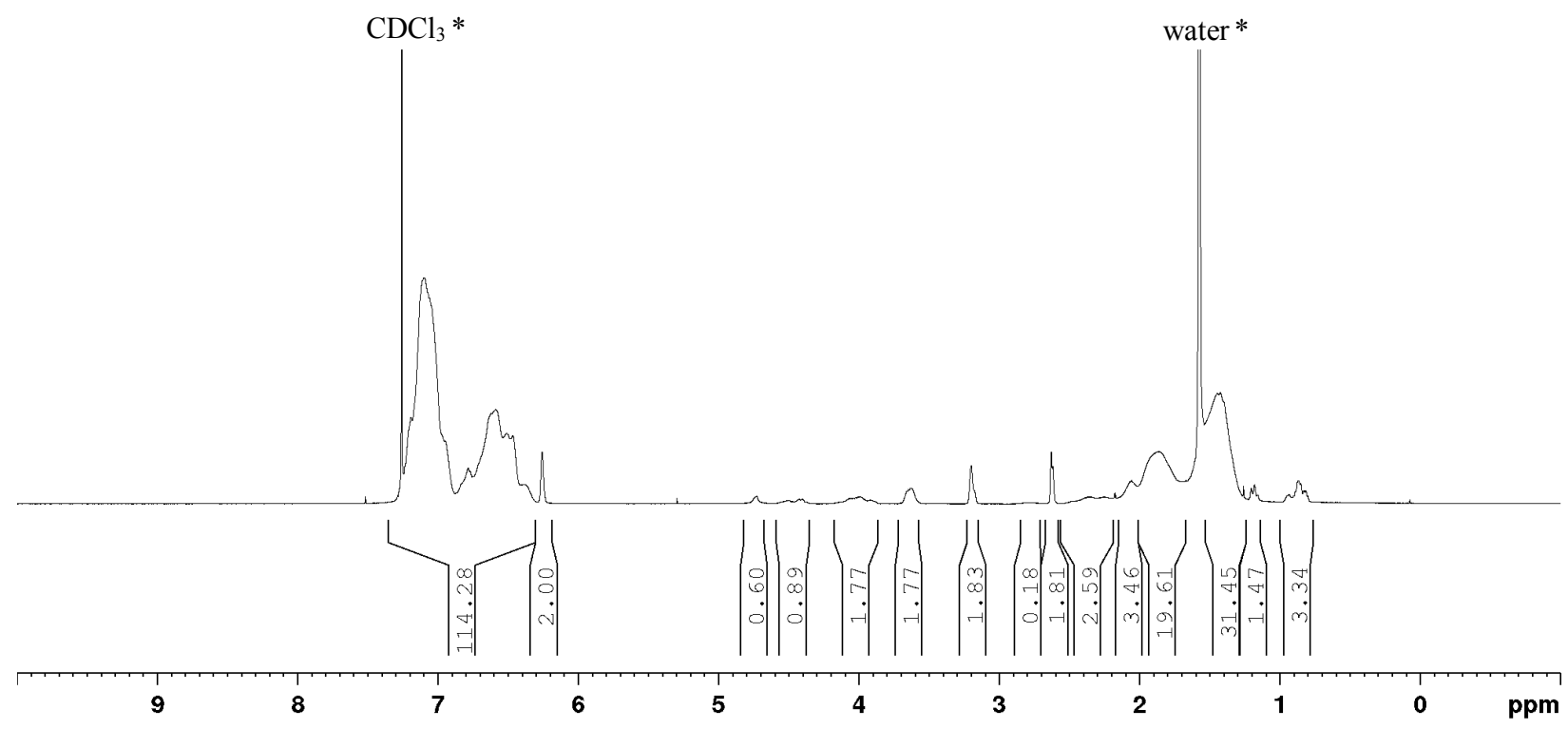

Figure S4. ${ }^{1} \mathrm{H}$ NMR spectrum of $\mathbf{S}$. $\mathrm{CDCl}_{3}, 400 \mathrm{MHz}$.

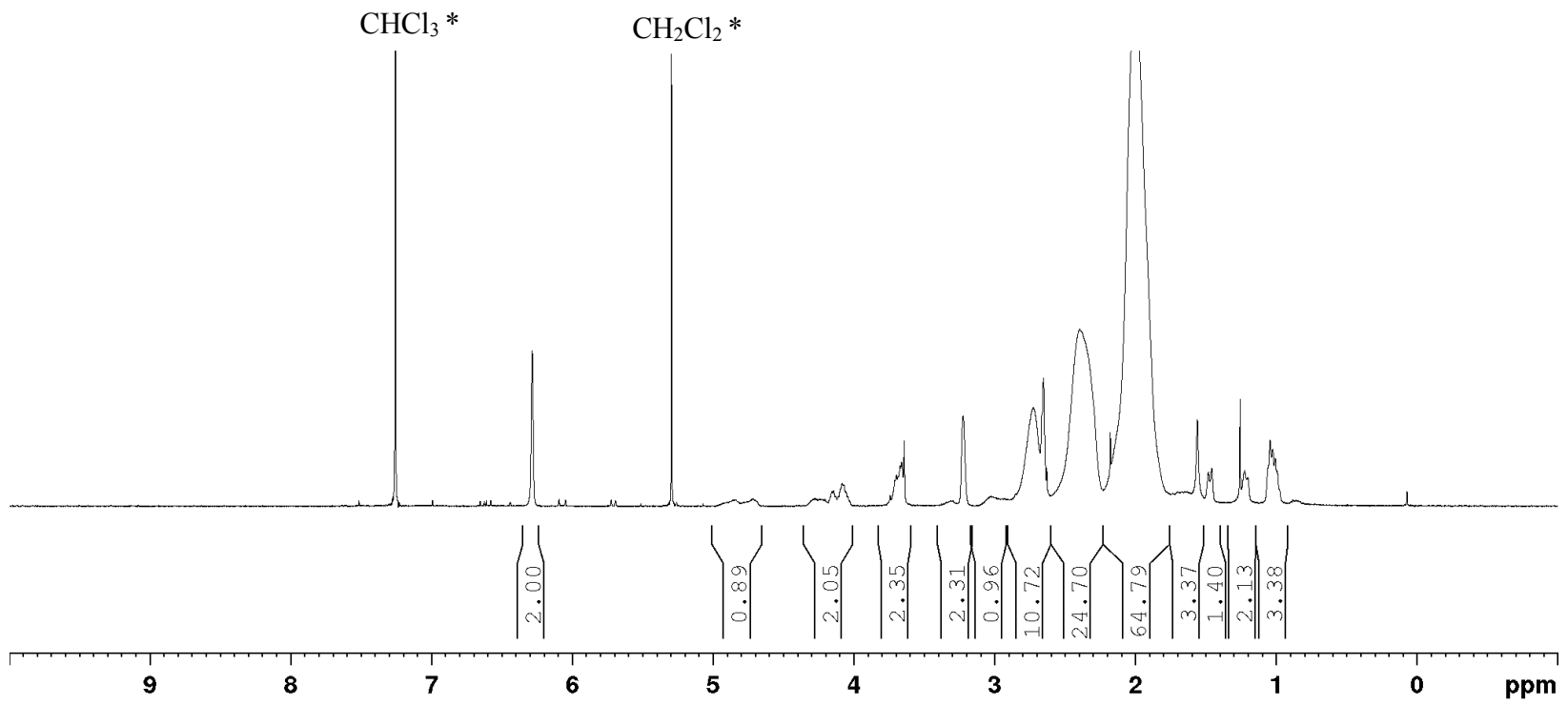

Figure S5. ${ }^{1} \mathrm{H}$ NMR spectrum of $\mathbf{F}$. $\mathrm{CDCl}_{3}, 400 \mathrm{MHz}$. 


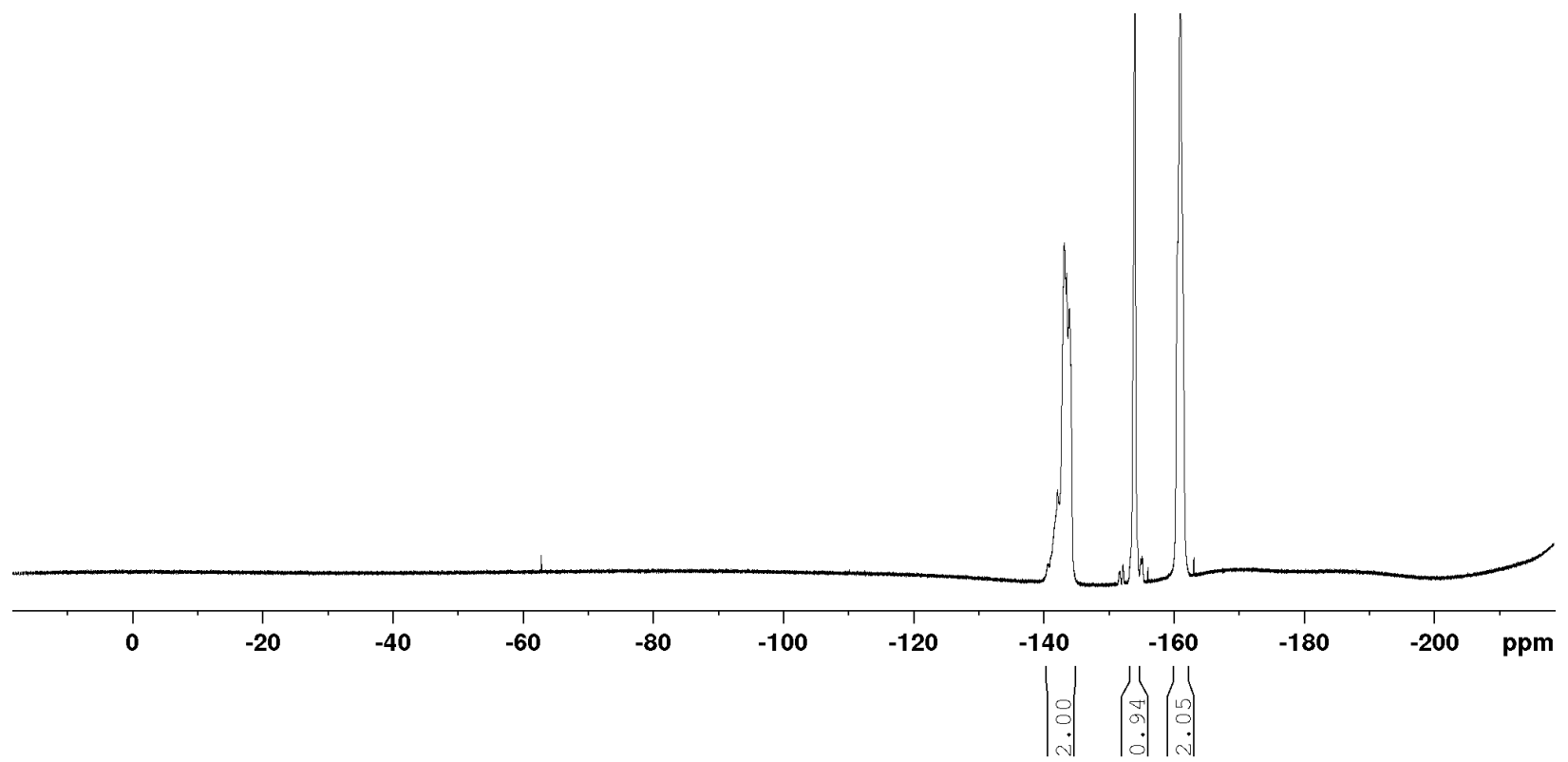

Figure S6. ${ }^{19} \mathrm{~F}\left\{{ }^{1} \mathrm{H}\right\} \mathrm{NMR}$ spectrum of $\mathbf{F} . \mathrm{CDCl}_{3}, 376 \mathrm{MHz}$.

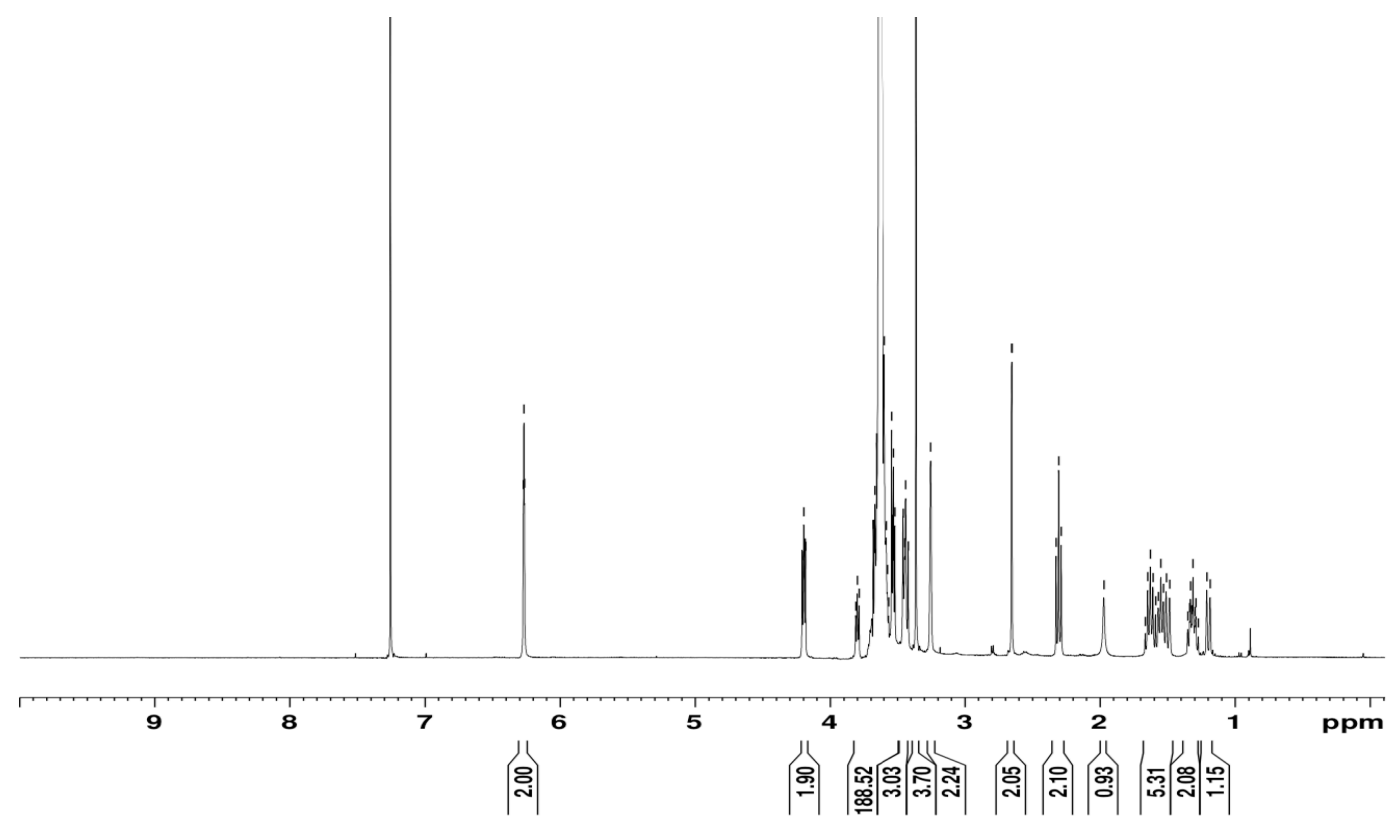

Figure S7. ${ }^{1} \mathrm{H}$ NMR spectrum of E. Acetone- $d_{6}, 400 \mathrm{MHz}$. 


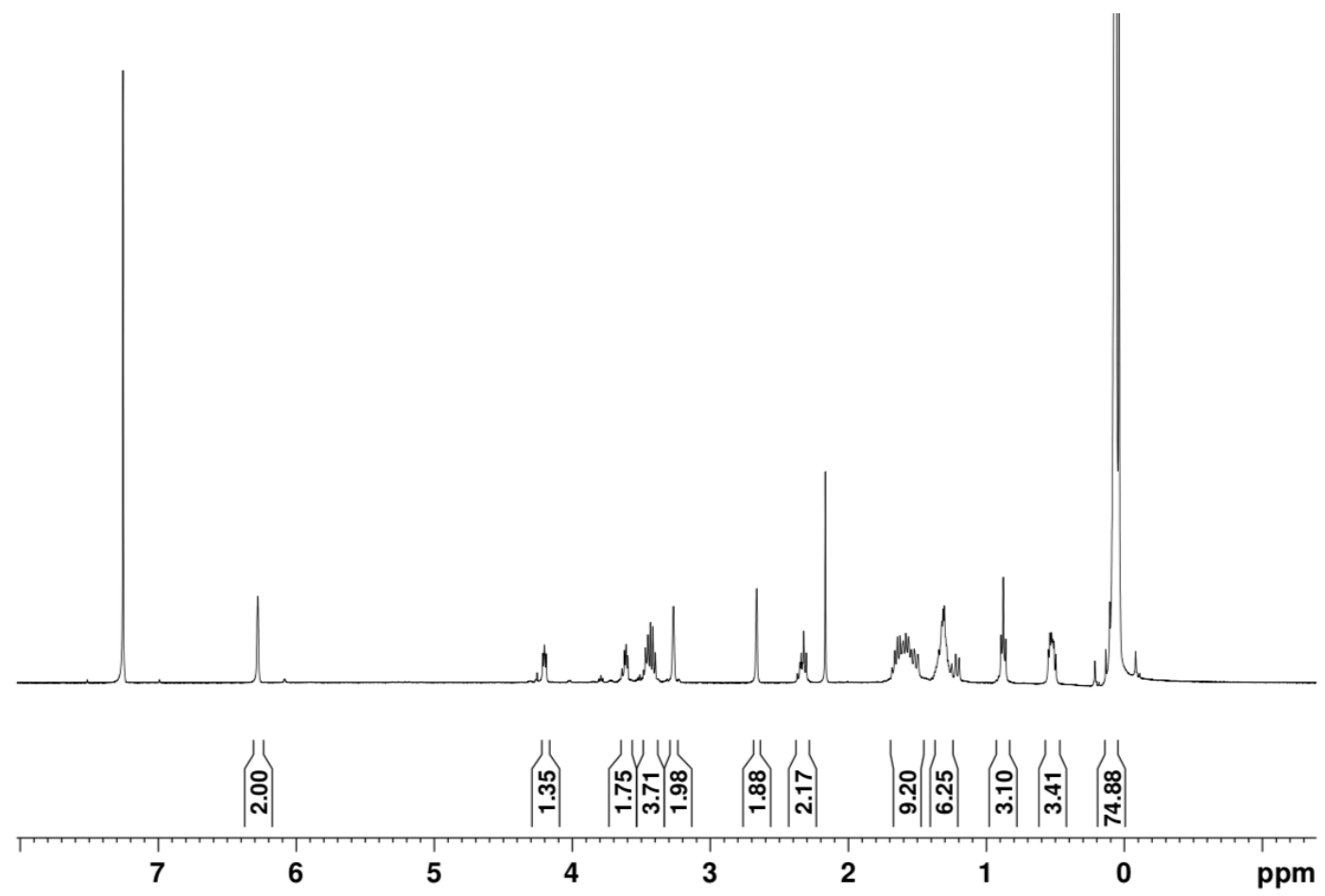

Figure S8. ${ }^{1} \mathrm{H}$ NMR spectrum of D. $\mathrm{CDCl}_{3}, 400 \mathrm{MHz}$ 

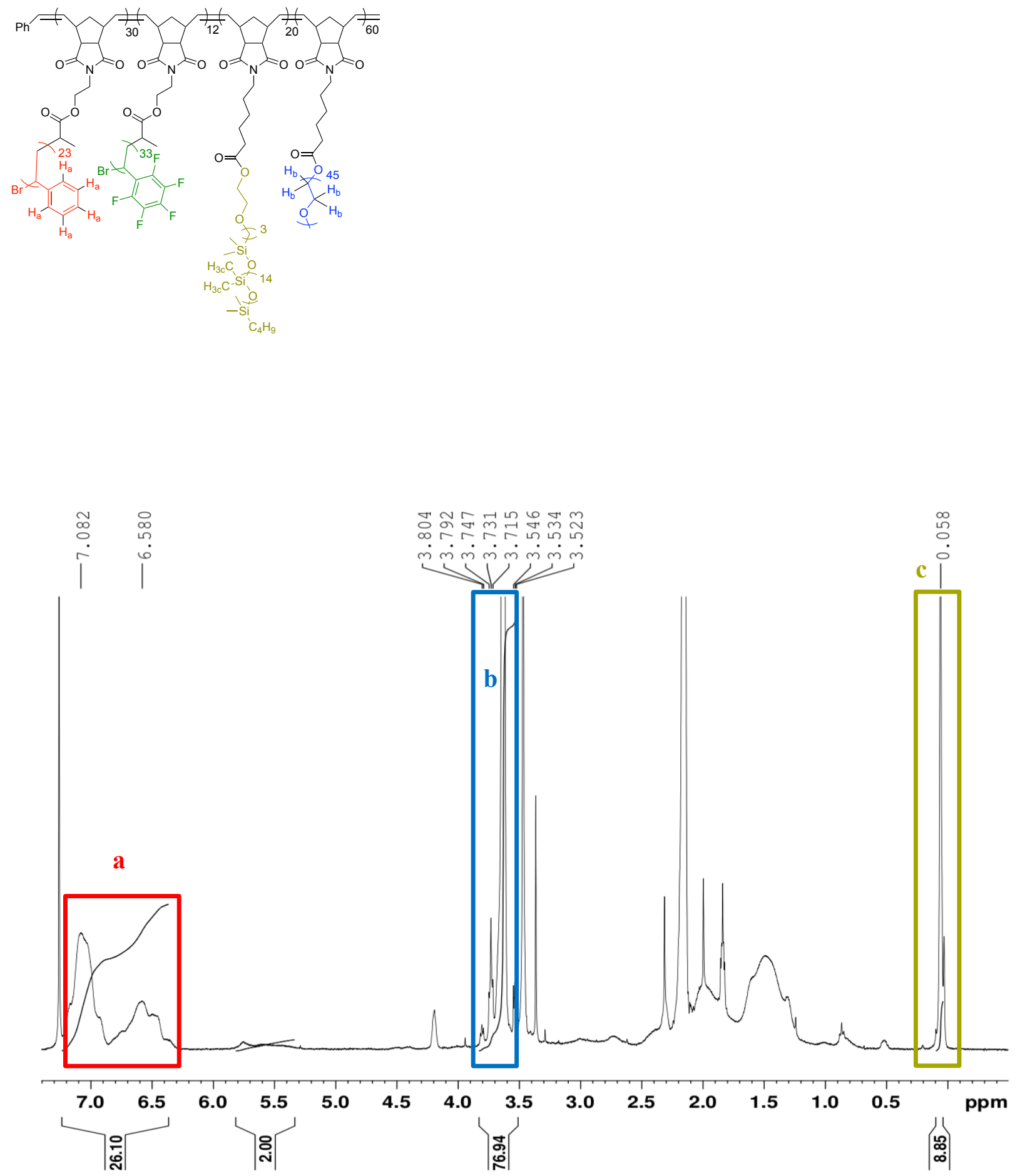

Figure S9. ${ }^{1} \mathrm{H}$ NMR spectrum of $\mathbf{S}_{\mathbf{3 0}}-\mathbf{F}_{\mathbf{1 2}}-\mathbf{D}_{\mathbf{2 0}}-\mathbf{E}_{\mathbf{6 0}} . \mathrm{CDCl}_{3}, 500 \mathrm{MHz}$ 

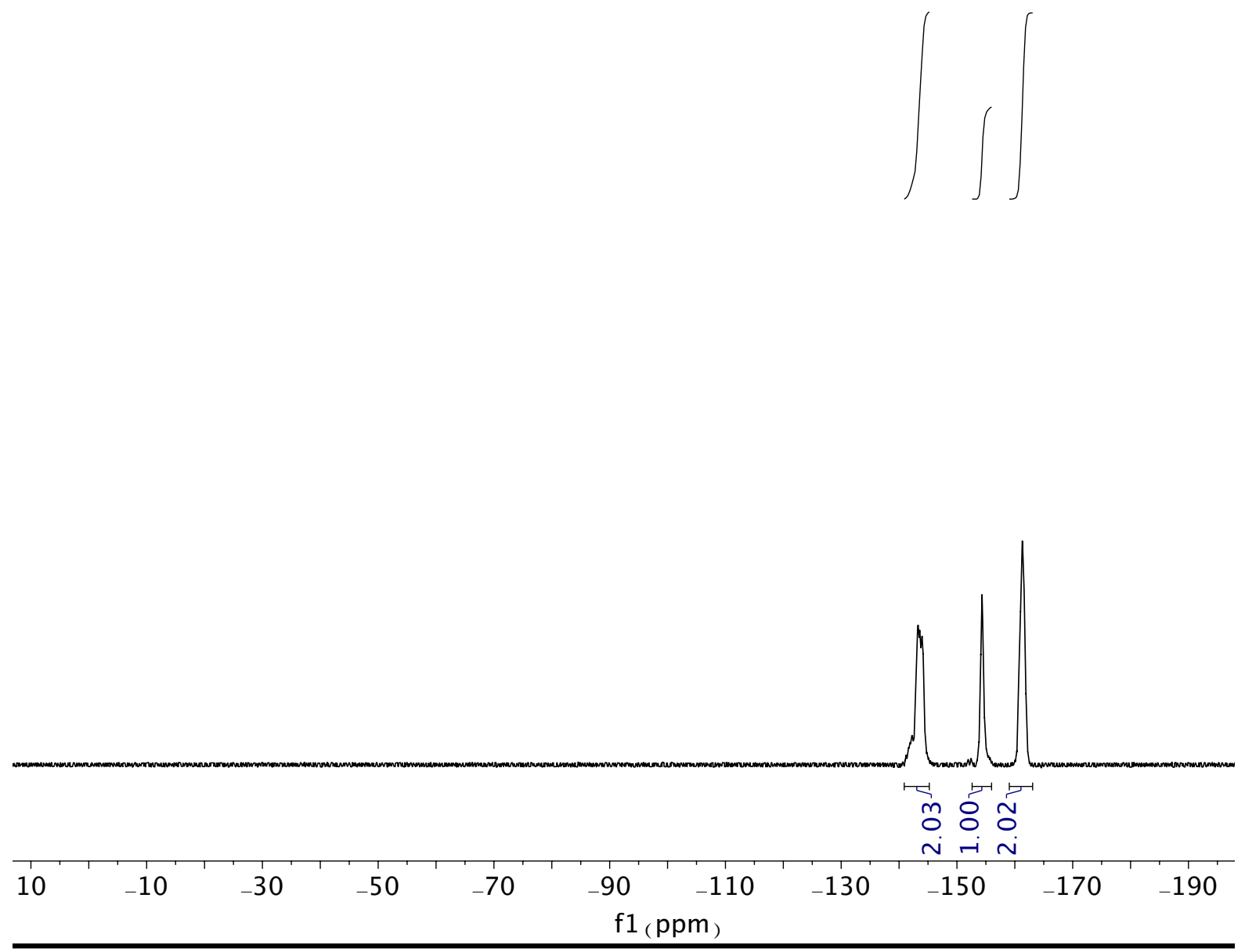

Figure S10. ${ }^{19} \mathrm{~F}\left\{{ }^{1} \mathrm{H}\right\}$ NMR spectrum of $\mathbf{S}_{\mathbf{3 0}}-\mathbf{F}_{\mathbf{1 2}}-\mathbf{D}_{\mathbf{2 0}}-\mathbf{E}_{\mathbf{6 0}} . \mathrm{CDCl}_{3}, 376 \mathrm{MHz}$ 

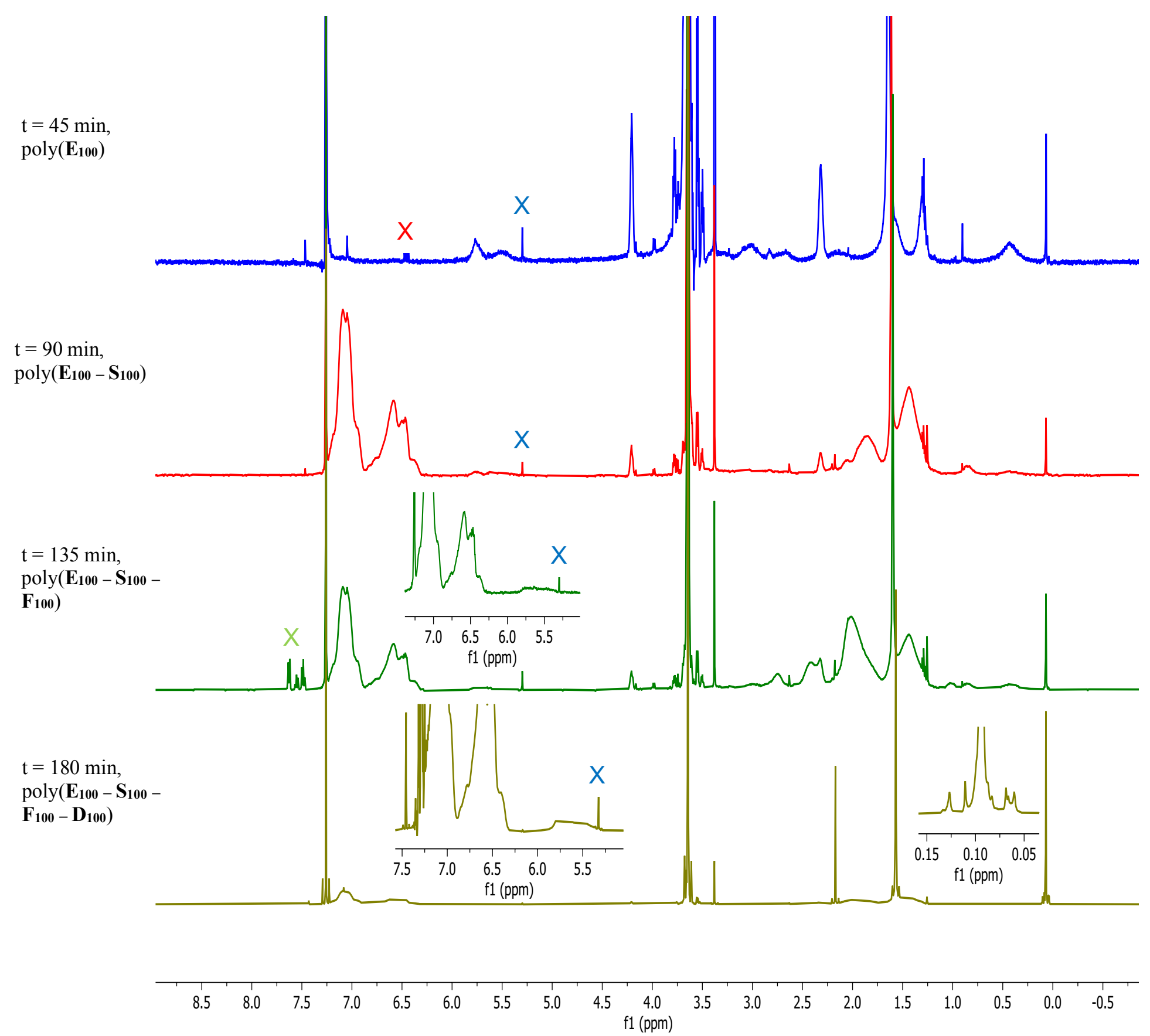

Figure S11. Stacked ${ }^{1} \mathrm{H}$ NMR spectra of tetrablock bottlebrush copolymer after addition of each macromonomer. $\mathrm{CDCl}_{3}, 600 \mathrm{MHz}$.

X-Ethyl vinyl ether residual peak, $X$ - dichloromethane solvent peak, $X-\alpha, \alpha, \alpha$,-trifluorotoluene solvent peak. 


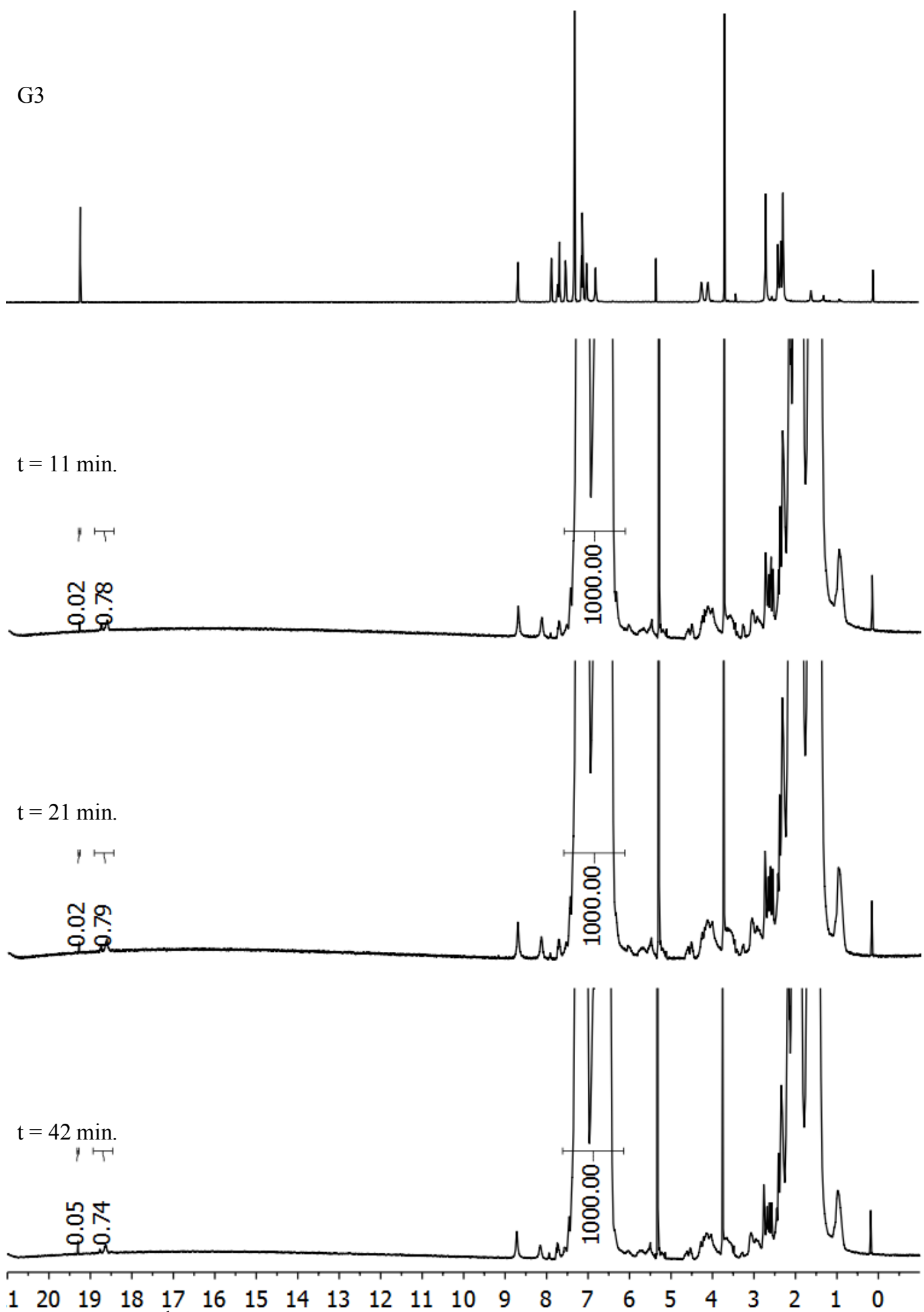

Figure S12. Stacked ${ }^{1} \mathrm{H}$ NMR spectra monitoring the Ru alkylidine proton signals. The signal at $\delta 19.21 \mathrm{ppm}$ corresponds to unreacted G3 and the signals between $\delta 18.81-18.57 \mathrm{ppm}$ correspond to a polymer-bound $\mathrm{Ru}$ alkylidine proton. The integrated region between $\delta 7.51-$ $6.37 \mathrm{ppm}$ correspond to aromatic styrenyl protons. $\mathrm{CDCl}_{3}, 500 \mathrm{MHz}$ 


\section{Gel Permeation Chromatography}

\section{Homoblock copolymers}

\begin{tabular}{|c|c|c|c|}
\hline \multirow{2}{*}{ Entry } & \multicolumn{2}{|c|}{ Mn (kDa) } & \multirow{2}{*}{ D } \\
\cline { 2 - 4 } & Theoretical & Experimental & 1.21 \\
\hline${ }^{a} \mathbf{E}_{15}$ & 50.7 & 43.3 & 1.10 \\
\hline${ }^{b} \mathbf{D}_{\mathbf{1 5}}$ & 26.0 & 26.3 & 1.08 \\
\hline${ }^{b} \mathbf{F}_{\mathbf{1 5}}$ & 43.0 & 75.0 & 1.13 \\
\hline${ }^{b} \mathbf{S}_{\mathbf{1 5}}$ & 34.5 & 39.7 & \\
\hline
\end{tabular}

Table S1. Molecular weight and dispersity of homo bottlebrush copolymers. ${ }^{a}$ DMF doped with $0.03 \mathrm{M} \mathrm{LiCl}$ solution was used as the eluent; ${ }^{b} \mathrm{THF}$ was used as the eluent.
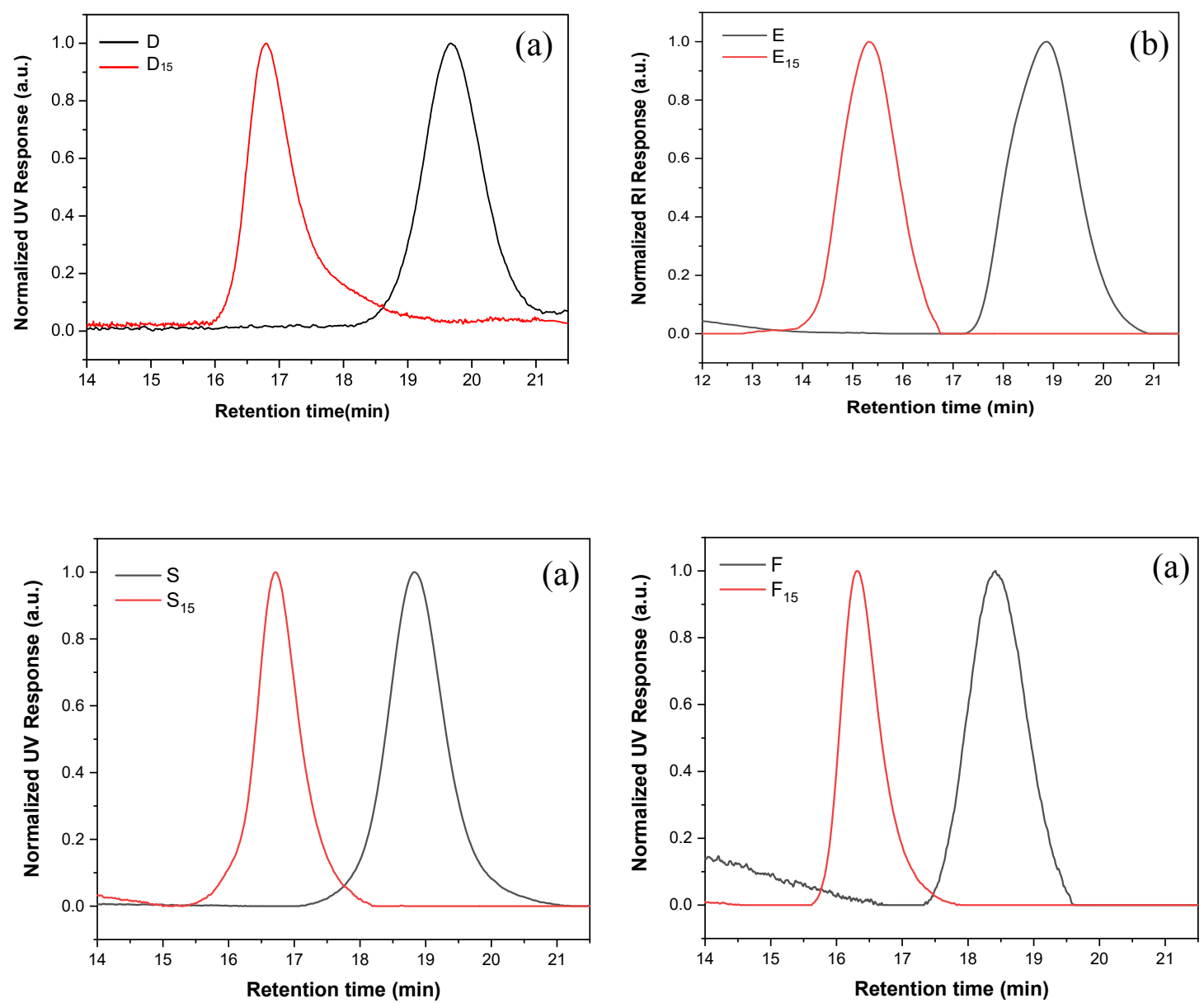

Figure S13. GPC chromatograms for homo bottlebrush polymers over laid with the respective macromonomers. (a)THF was used as the eluent; (b) DMF doped with $0.03 \mathrm{M} \mathrm{LiCl}$ solution was used as the eluent. 


\section{Subsequent addition to show block incorporation for triblock copolymers}

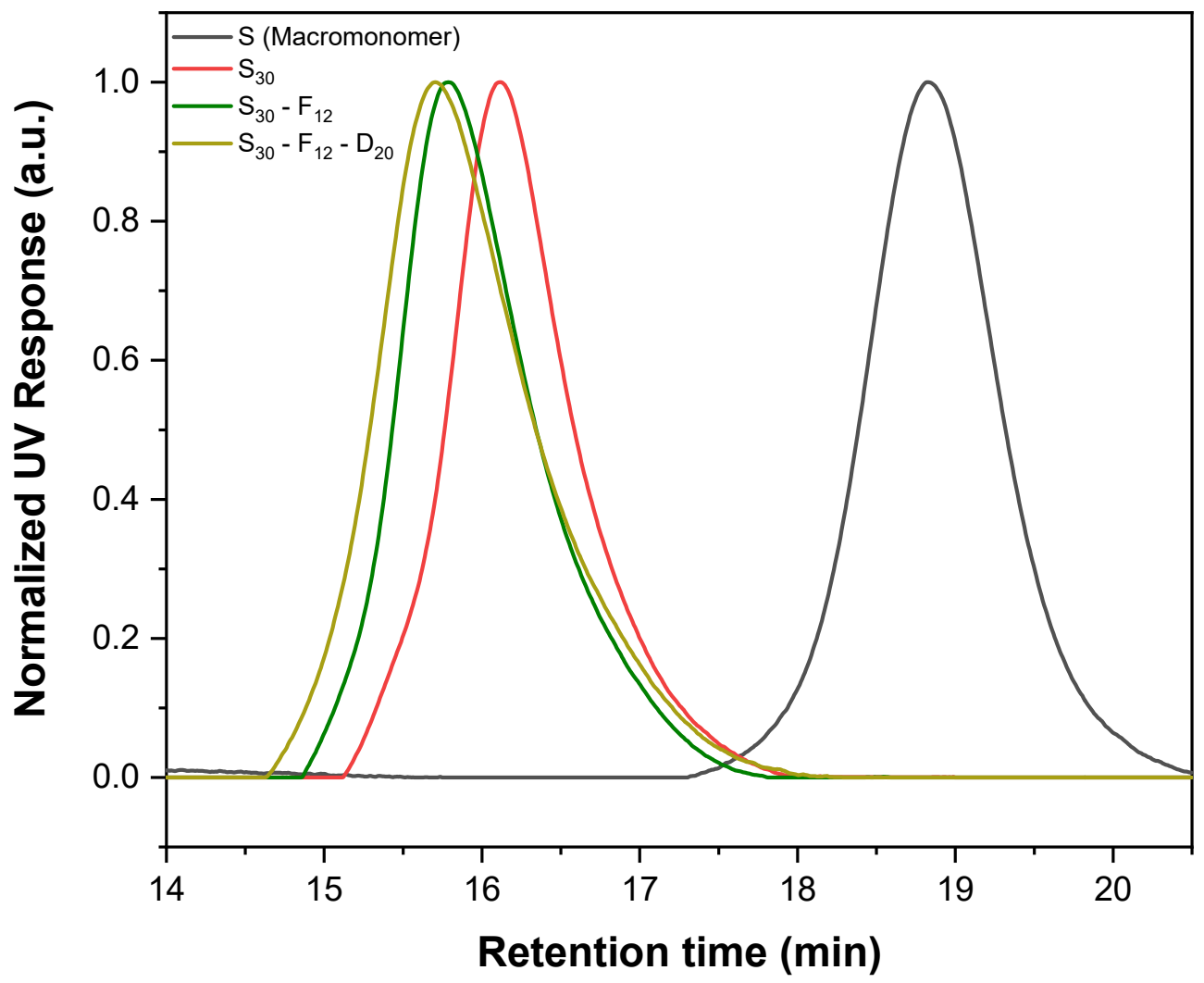

Figure S14. GPC chromatogram of triblock $\mathbf{S}_{\mathbf{3 0}}-\mathbf{F}_{\mathbf{1 2}}-\mathbf{D}_{\mathbf{2 0}}$ after the addition of each macromonomer. The peaks are unimodal and narrow, indicating low molar mass dispersity. Complete consumption is observed at each stage prior to addition of subsequent block. THF was used as the eluent. 


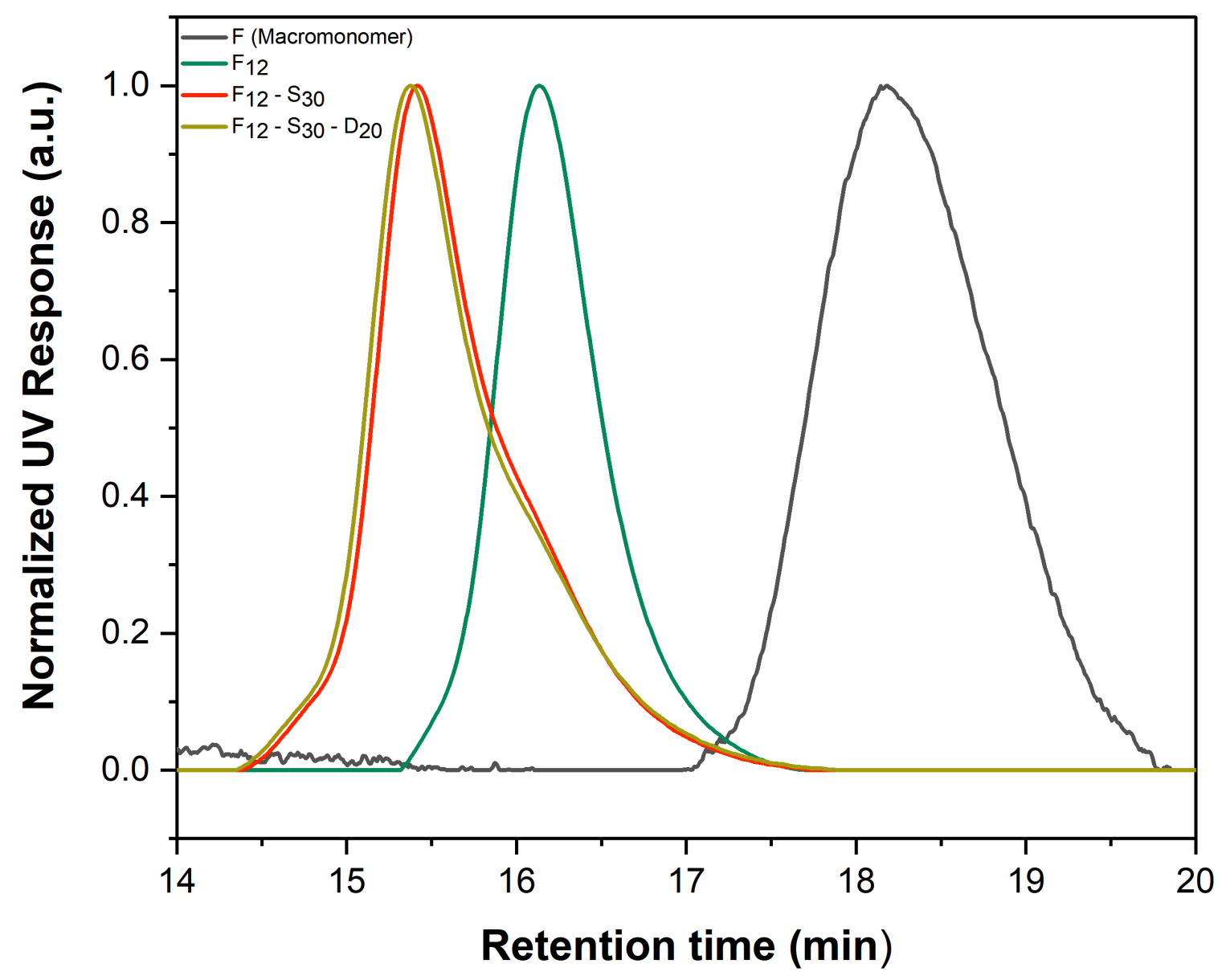

Figure S15. GPC chromatogram of triblock $\mathbf{F}_{\mathbf{1 2}}-\mathbf{S}_{\mathbf{3 0}}-\mathbf{D}_{\mathbf{2 0}}$ after the addition of each macromonomer. Complete consumption is observed at each stage prior to addition of subsequent block. THF was used as the eluent. 


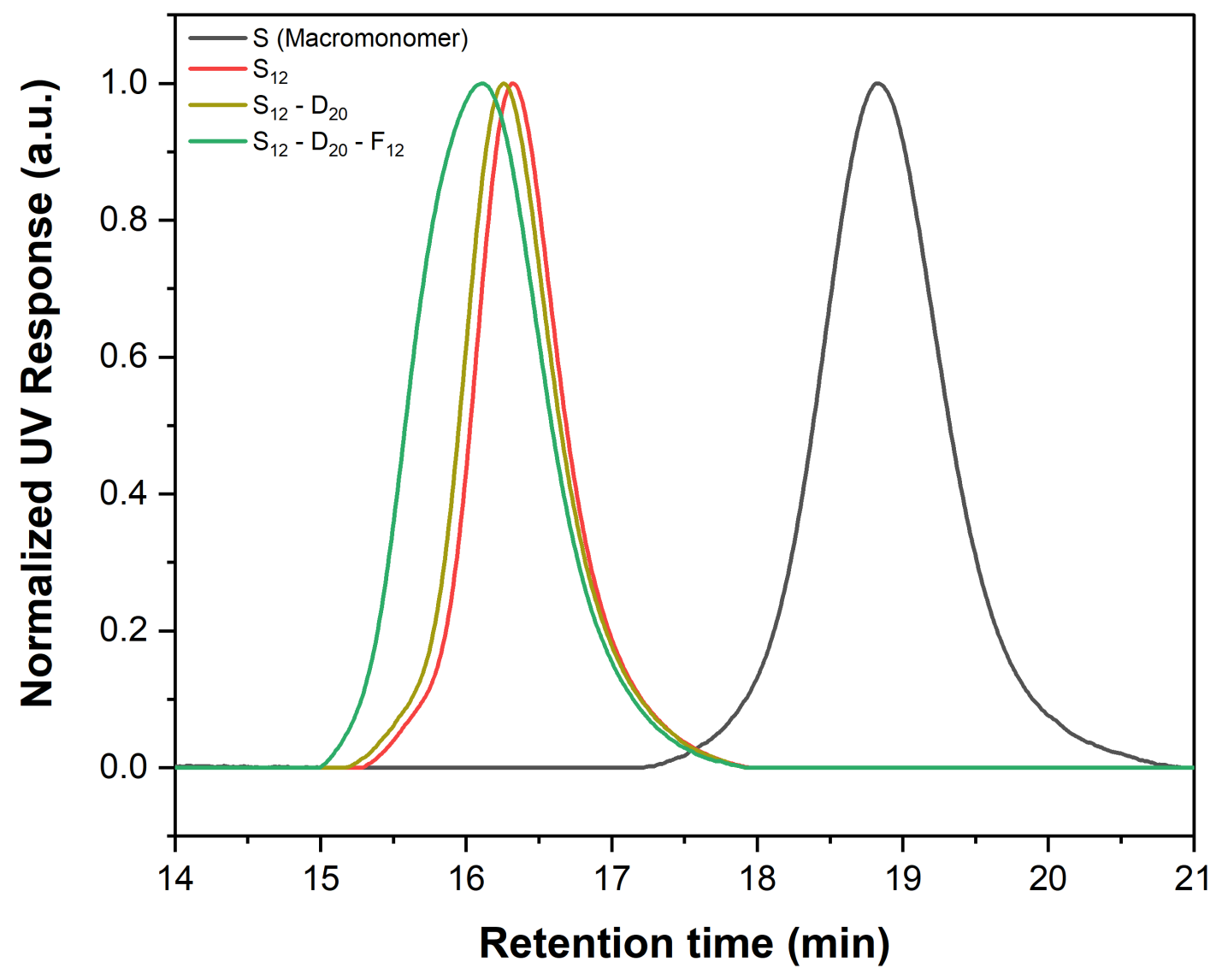

Figure S16. GPC chromatogram of triblock $\mathbf{S}_{\mathbf{3 0}}-\mathbf{D}_{\mathbf{2 0}}-\mathbf{F}_{\mathbf{1 2}}$ after the addition of each macromonomer. Complete consumption is observed at each stage prior to addition of subsequent block. THF was used as the eluent. 


\section{Tetrablock copolymers (Polymers 1 - 6)}

THF with 1 vol\% triethylamine is used as the eluent

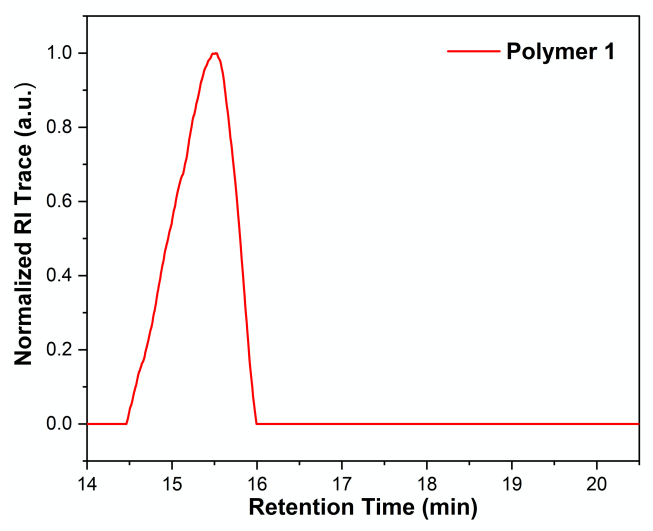

Figure S17. GPC trace of Polymer 1

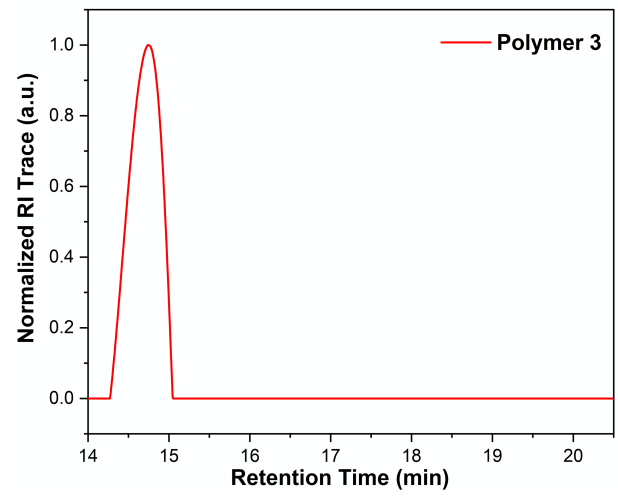

Figure S19. GPC trace of Polymer 3

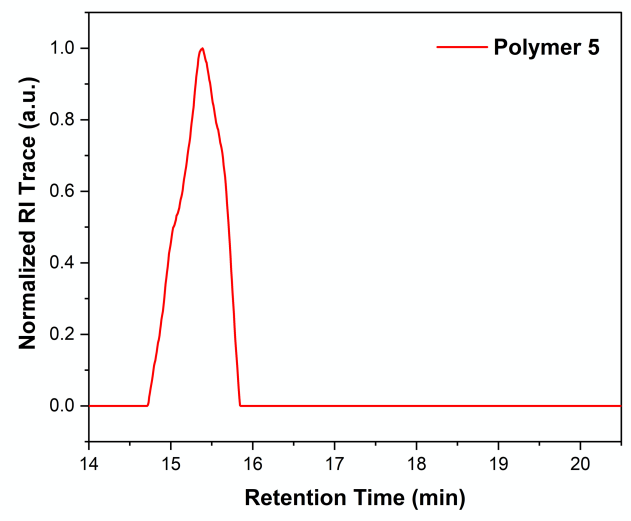

Figure S21. GPC trace of Polymer 5

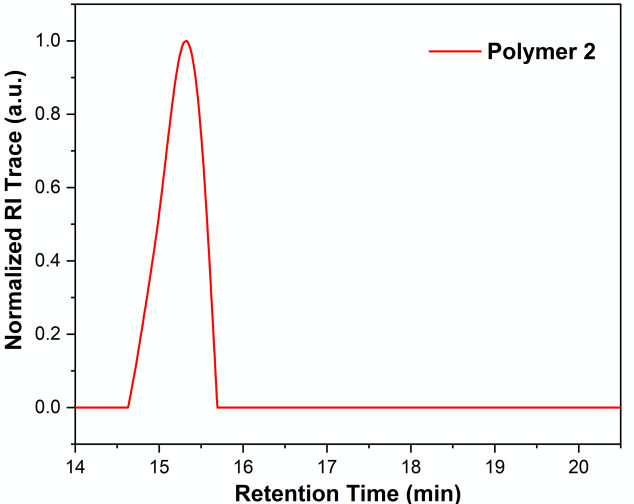

Figure S18. GPC trace of Polymer 2

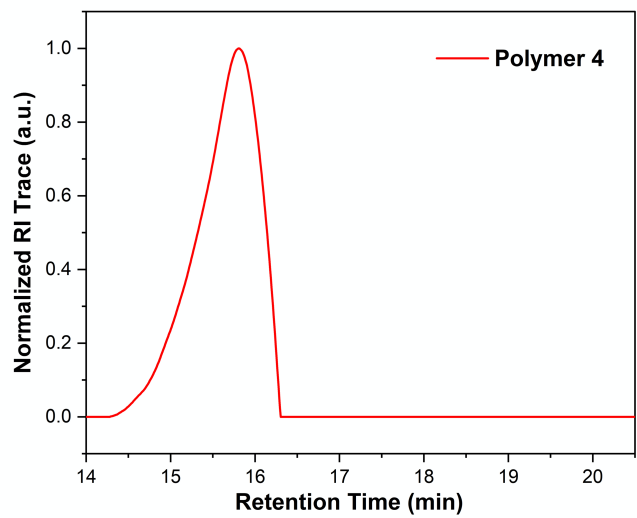

Figure S20. GPC trace of Polymer 4

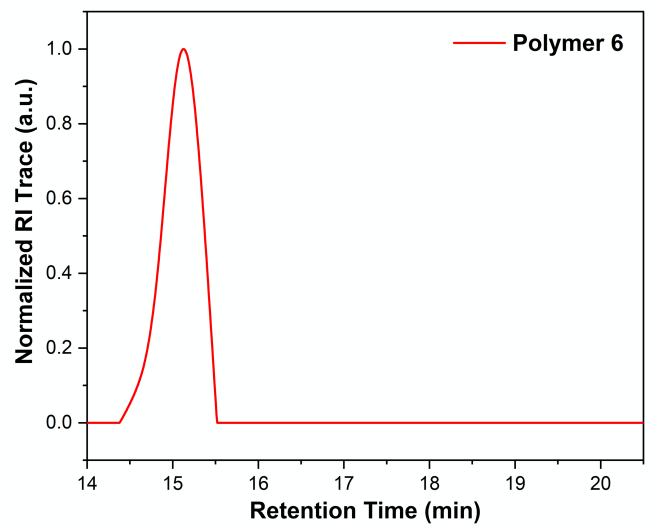

Figure S22. GPC trace of Polymer 6 
IV. Subsequent addition to show block incorporation for tetrablock copolymers (Polymers 1 - 5)

Polymer $1^{\text {a }}$

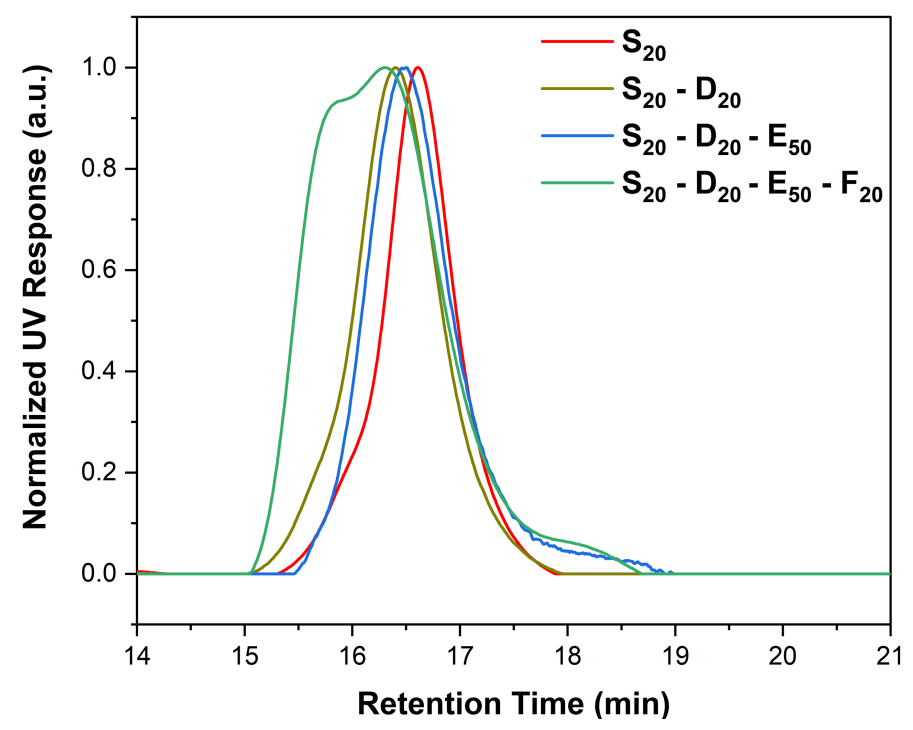

Polymer $2^{\mathrm{a}}$

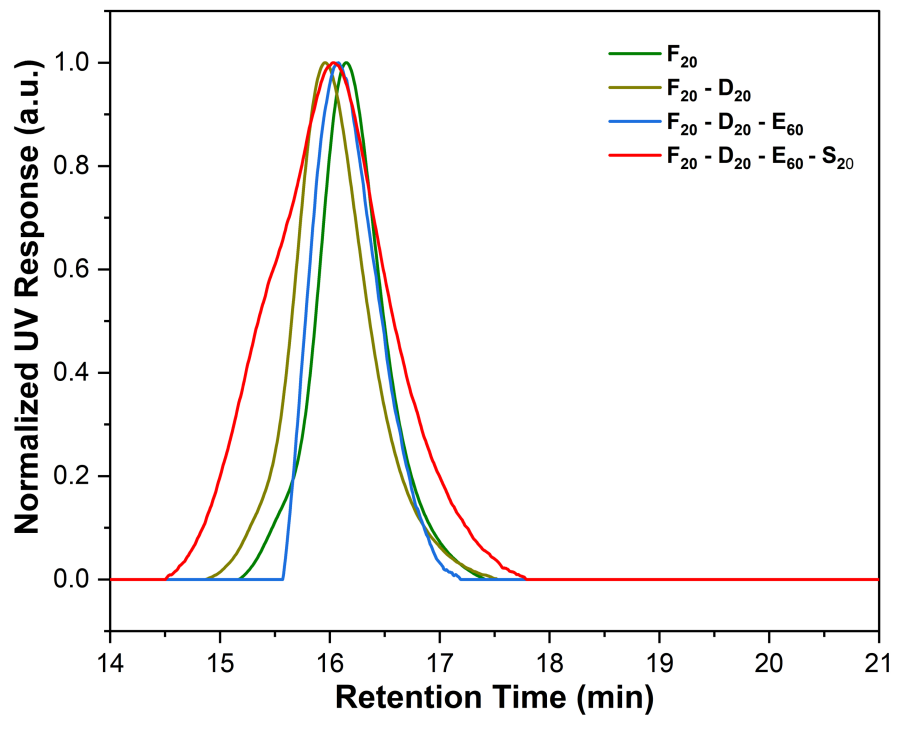

Polymer $3^{\text {a }}$

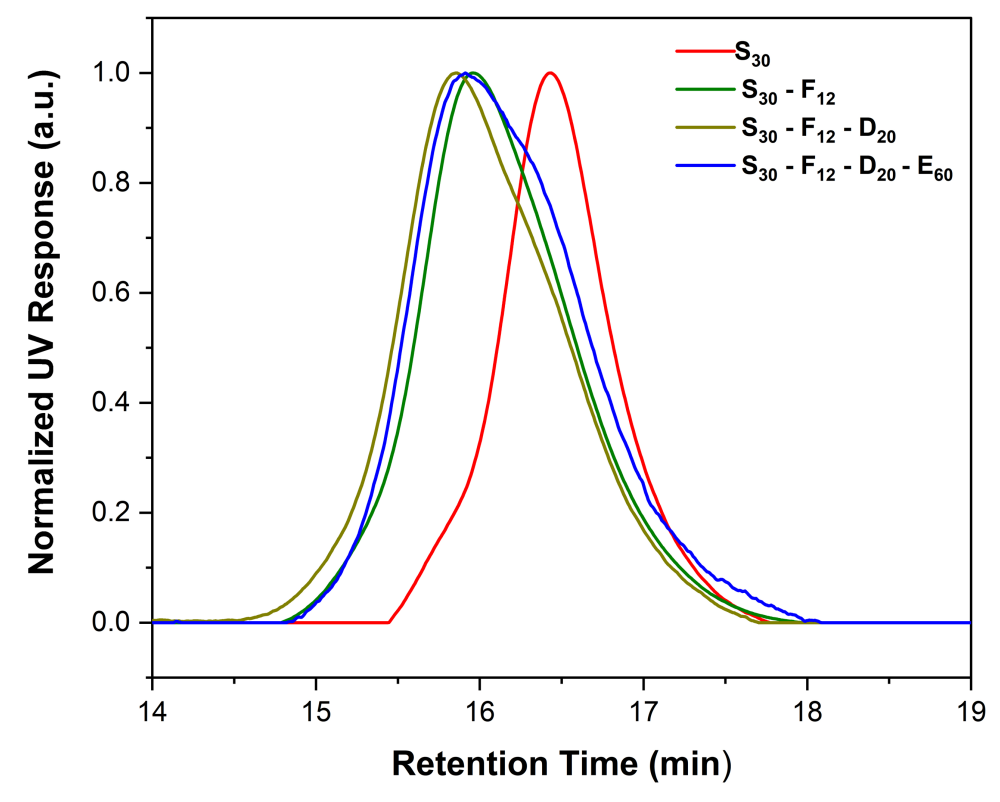




\section{Polymer $4^{\mathrm{b}}$}

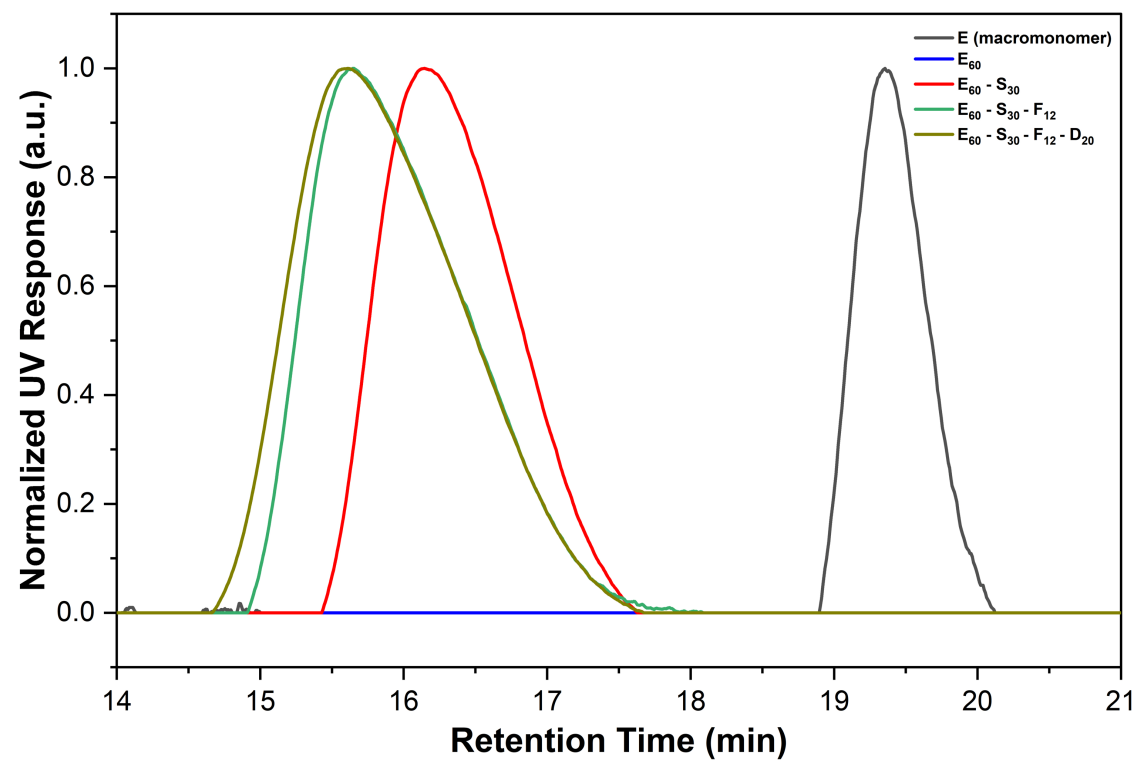

Polymer $5^{\mathrm{b}}$

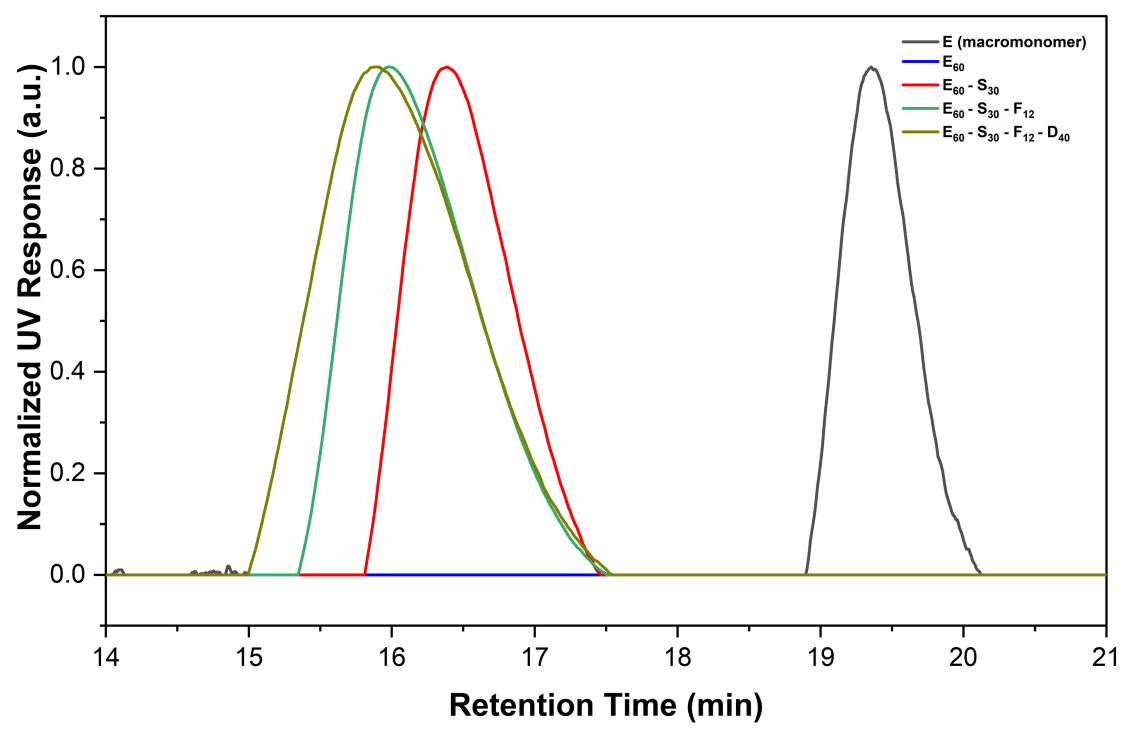

Figure S23. GPC chromatograms of Polymers $\mathbf{1}-\mathbf{5}$ after the addition of each macromonomer. THF with 1 vol\% triethylamine was used as the eluent. By NMR spectroscopy, complete macromonomer consumption is observed at each stage prior to the addition of the next macromonomer. ${ }^{a} \mathrm{~A}$ decrease in molecular weight is observed upon the sequential addition of the $\mathbf{E}$ block to the $\mathbf{D}$ block. This phenomenon was attributed to the decrease in the swelling of the PDMS block upon the addition of PEG as described in the literature. ${ }^{9,10}{ }^{b}$ The PEG homoblock $\mathbf{E}$ did not elute in the chosen eluent. As described in the literature, this phenomenon can be attributed to column interactions of the PEG polymer with the hydrophobic column. ${ }^{11}$ 
Differential Scanning Calorimetry

\begin{tabular}{|c|c|c|c|}
\hline Polymer & Composition & $\mathbf{T}_{\mathbf{g}}\left({ }^{\circ} \mathbf{C}\right)$ & $\mathbf{T}_{\mathbf{m}}\left({ }^{\circ} \mathbf{C}\right)$ \\
\hline 7 & $\mathbf{D}_{100}$ & -121 & - \\
\hline 8 & $\mathbf{E}_{100}$ & - & 52 \\
\hline 9 & $\mathbf{S}_{100}$ & 108 & - \\
\hline 10 & $\mathbf{F}_{100}$ & 99 & - \\
\hline 11 & $\mathbf{E}_{100}-\mathbf{D}_{100}$ & -135 & 52 \\
\hline 12 & $\mathbf{E}_{100}-\mathbf{S}_{100}-\mathbf{F}_{100}-\mathbf{D}_{100}$ & $\mathbf{1 0 5}$ & $\mathbf{5 2}$ \\
\hline
\end{tabular}

I. DSC traces of homoblock and tetrablock bottlebrush copolymers
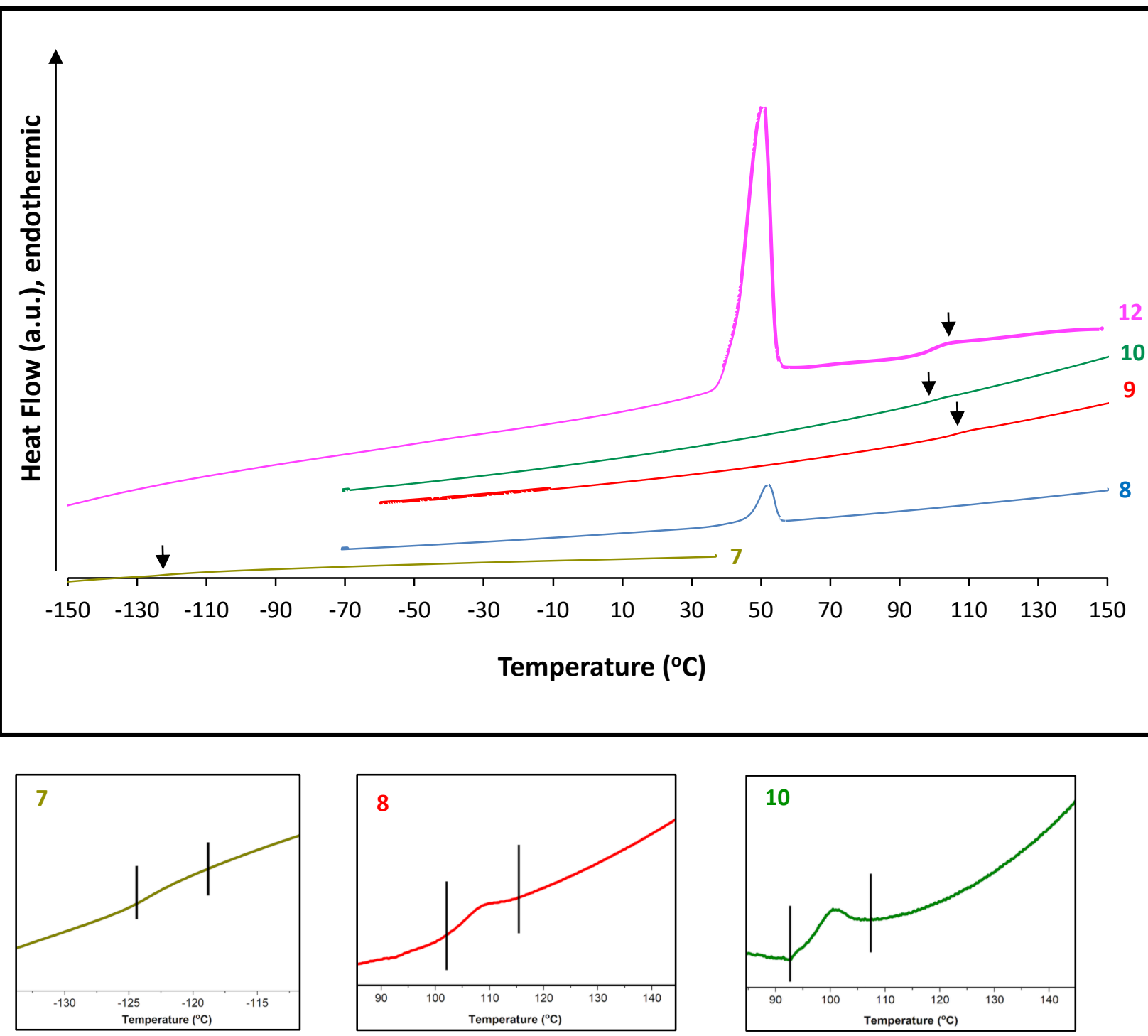
II. DSC traces to show the incorporation of the siliphilic and hydrophilic block in polymer 11

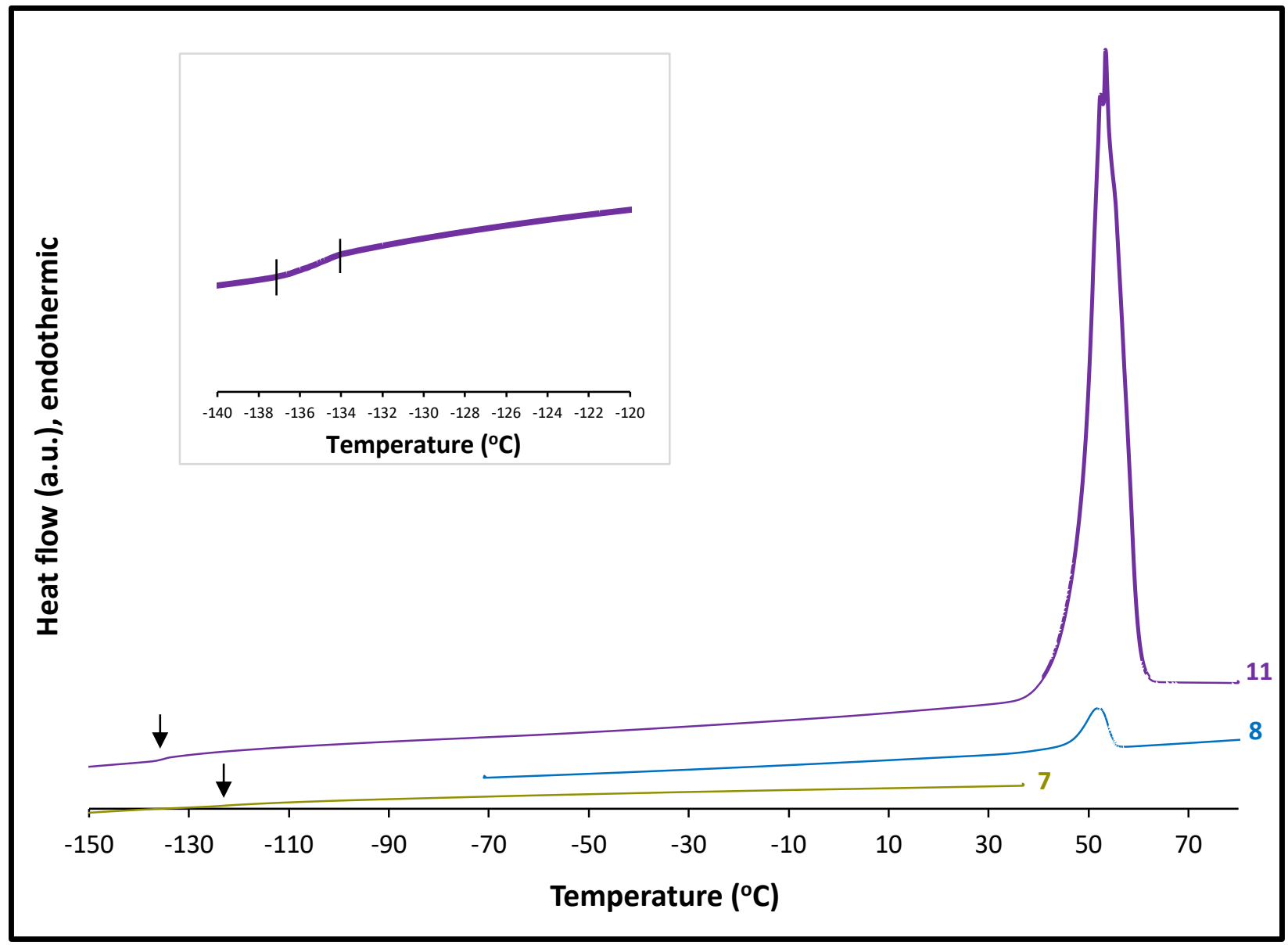

Figure S24. DSC traces of bottlebrush copolymers to demonstrate block incorporation. The arrows indicate the $\mathrm{Tg}$.

\section{Percent Composition Calculation}

Percent composition of $\mathbf{S}, \mathbf{E}$, and $\mathbf{D}$ in the tetrablock bottlebrush copolymer were determined from the following equation:

$$
\begin{gathered}
\% \boldsymbol{S}=\frac{\frac{\frac{A_{S}}{5}}{N_{S}}}{\frac{A_{\text {vinyl }}}{2}} \times 100 \% \quad \% \boldsymbol{E}=\frac{\frac{\frac{A_{E}}{4}}{N_{E}}}{\frac{A_{\text {vinyl }}}{2}} \times 100 \% \\
\% \boldsymbol{D}=\frac{\frac{A_{\boldsymbol{D}} / 6}{N_{\boldsymbol{D}}}}{A_{\text {vinyl }} / 2} \times 100
\end{gathered}
$$


Where $A_{\boldsymbol{S}}=$ the integral of aromatic protons from $\delta 6.40-7.25 \mathrm{ppm}, A_{\boldsymbol{E}}=$ the integral of methylene protons from $\delta 3.44-3.80 \mathrm{ppm}, A_{\boldsymbol{D}}=$ the integral of silyl protons from $\delta 0.08-0.12 \mathrm{ppm}$, and $A_{\text {vinyl }}=$ the sum of the integrals of the vinyl protons from $\delta 5.31-6.00 \mathrm{ppm} . N_{S}=23, N_{E}=45$ and $N_{\boldsymbol{D}}=14$ are the average degree of polymerization and were calculated from the ${ }^{1} \mathrm{H}$ NMR spectrum of each macromonomer.

\section{Dynamic Light Scattering Analysis}

Procedure for micelle formation

$9 \mathrm{mg}$ of polymer was dissolved in $3 \mathrm{~mL}$ of THF to obtain a solution with a concentration of 3 $\mathrm{mg} / \mathrm{mL}$. The solution was placed in a $1 \mathrm{kD}$ dialysis bag and the solvent was exchanged with water by placing the dialysis bag in water. Dialysis water was replaced daily for one week to induce micelle assembly. After one week, the solution from the dialysis bag was passed through a 0.45 $\mu \mathrm{m}$ syringe filter and analyzed by DLS and Cryo-TEM.

Table S2. Summary of particle sizes obtained by DLS.

\section{Diblocks:}

\begin{tabular}{|c|c|c|c|}
\hline Polymer & Composition & $\begin{array}{c}\mathbf{D}_{\mathbf{h}, \mathbf{a v g}} \\
\mathbf{( n m )}\end{array}$ & PDI \\
\hline $\mathbf{A}$ & $\mathbf{E}_{\mathbf{6 0}}-\mathbf{D}_{\mathbf{2 0}}$ & 122.1 & 0.464 \\
\hline $\mathbf{B}$ & $\mathbf{E}_{\mathbf{6 0}}-\mathbf{S}_{\mathbf{2 5}}$ & 130 & 0.29 \\
\hline $\mathbf{C}$ & $\mathbf{E}_{\mathbf{6 0}}-\mathbf{F}_{\mathbf{1 5}}$ & 100 & 0.16 \\
\hline
\end{tabular}

\section{Triblocks:}

\begin{tabular}{|c|c|c|c|}
\hline Polymer & Composition & $\begin{array}{c}\mathbf{D}_{\mathbf{h}, \text { avg }} \\
(\mathbf{n m})\end{array}$ & PDI \\
\hline $\mathbf{1 3}$ & $\mathbf{S}_{\mathbf{3 5}}-\mathbf{F}_{\mathbf{1 5}}-\mathbf{E}_{\mathbf{5 0}}$ & 430 & 0.17 \\
\hline
\end{tabular}




\begin{tabular}{|l|l|l|l|}
\hline $\mathbf{1 4}$ & $\mathbf{F}_{\mathbf{1 5}}-\mathbf{E}_{\mathbf{5 0}}-\mathbf{S}_{\mathbf{3 5}}$ & 241 & 0.14 \\
\hline $\mathbf{1 5}$ & $\mathbf{E}_{\mathbf{6 0}}-\mathbf{S}_{\mathbf{3 0}}-\mathbf{D}_{\mathbf{2 0}}$ & 151 & 0.07 \\
\hline $\mathbf{1 6}$ & $\mathbf{E}_{\mathbf{6 0}}-\mathbf{F}_{\mathbf{4 5}}-\mathbf{D}_{\mathbf{1 5}}$ & 107 & 0.12 \\
\hline
\end{tabular}

\section{Tetrablocks:}

\begin{tabular}{|c|c|c|c|}
\hline Polymer & Composition & $\begin{array}{c}\mathbf{D}_{\mathbf{h}, \text { avg }} \\
(\mathbf{n m})\end{array}$ & PDI \\
\hline $\mathbf{1}$ & $\mathbf{S}_{\mathbf{2 0}}-\mathbf{D}_{\mathbf{2 0}}-\mathbf{E}_{\mathbf{5 0}}-\mathbf{F}_{\mathbf{2 0}}$ & 109 & 0.21 \\
\hline $\mathbf{2}$ & $\mathbf{F}_{\mathbf{2 0}}-\mathbf{D}_{\mathbf{2 0}}-\mathbf{E}_{\mathbf{5 0}}-\mathbf{S}_{\mathbf{2 0}}$ & 79 & 0.16 \\
\hline $\mathbf{3}$ & $\mathbf{S}_{\mathbf{3 0}}-\mathbf{F}_{\mathbf{1 2}}-\mathbf{D}_{\mathbf{2 0}}-\mathbf{E}_{\mathbf{6 0}}$ & 229 & 0.08 \\
\hline $\mathbf{4}$ & $\mathbf{E}_{\mathbf{6 0}}-\mathbf{S}_{\mathbf{3 0}}-\mathbf{F}_{\mathbf{1 2}}-\mathbf{D}_{\mathbf{2 0}}$ & 190 & 0.08 \\
\hline $\mathbf{5}$ & $\mathbf{E}_{\mathbf{6 0}}-\mathbf{S}_{\mathbf{3 0}}-\mathbf{F}_{\mathbf{1 2}}-\mathbf{D}_{\mathbf{4 0}}$ & 251 & 0.11 \\
\hline $\mathbf{6}$ & $\mathbf{S}_{\mathbf{3 0}}-\mathbf{E}_{\mathbf{6 0}}-\mathbf{F}_{\mathbf{1 2}}-\mathbf{D}_{\mathbf{2 0}}$ & 175 & 0.10 \\
\hline
\end{tabular}




\section{DLS Traces}

\section{Diblocks}

A. $\mathbf{E}_{60}-\mathbf{D}_{20}$

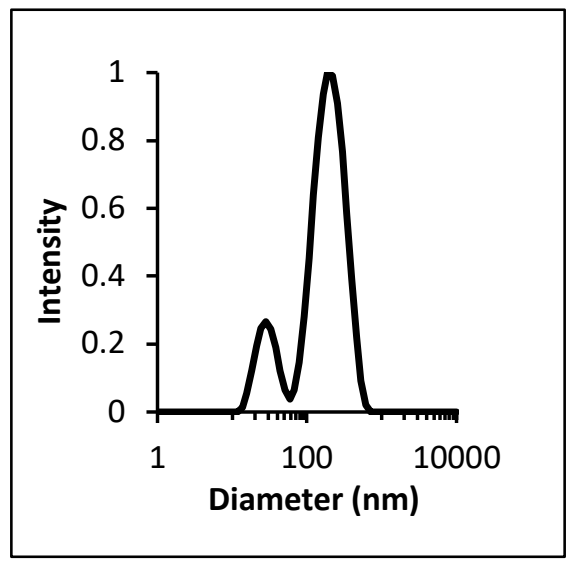

II. Triblocks

13. $\mathrm{S}_{35}-\mathrm{F}_{15}-\mathrm{E}_{50}$

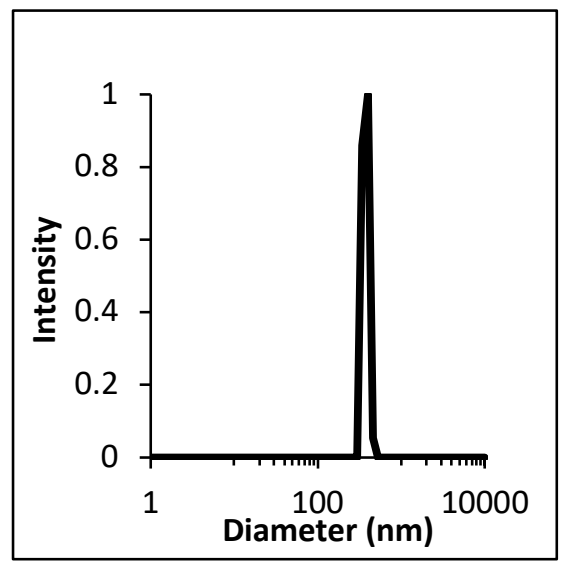

B. $\mathbf{E}_{60}-\mathbf{S}_{25}$

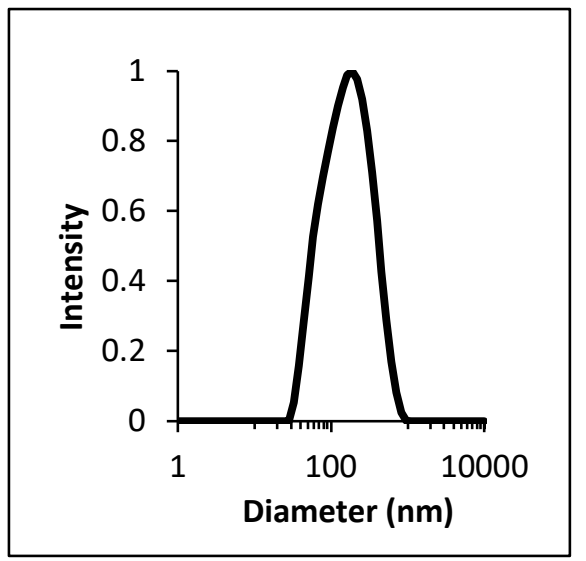

14. $F_{15}-E_{60}-S_{35}$

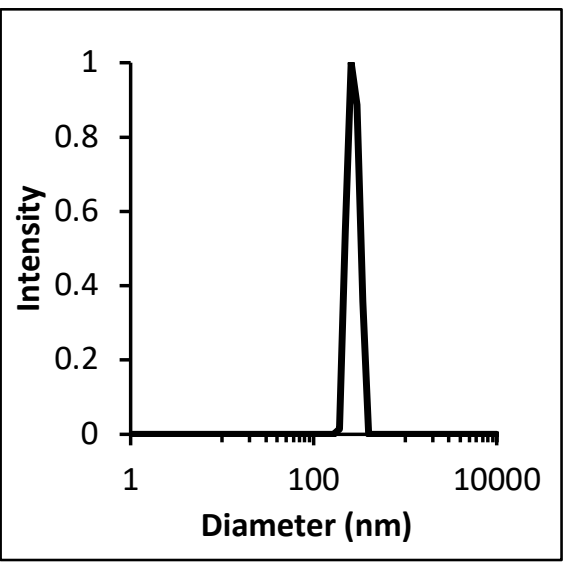

16. $E_{60}-F_{45}-D_{15}$

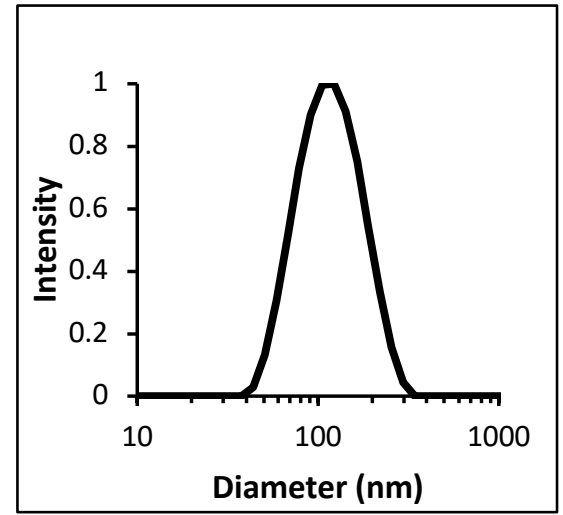

C. $\mathrm{E}_{60}-\mathrm{F}_{15}$

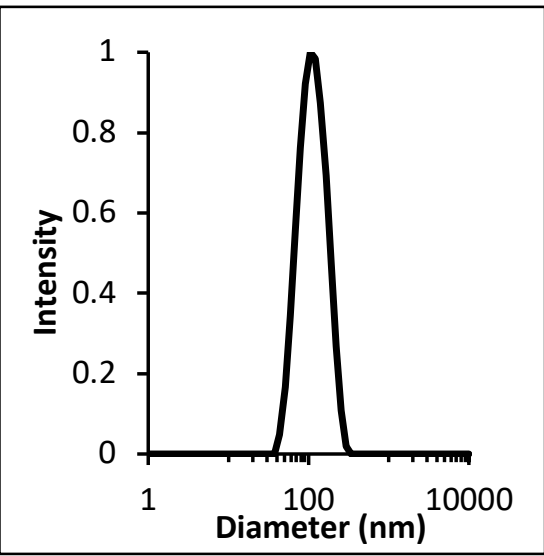

15. $E_{60}-S_{30}-D_{20}$

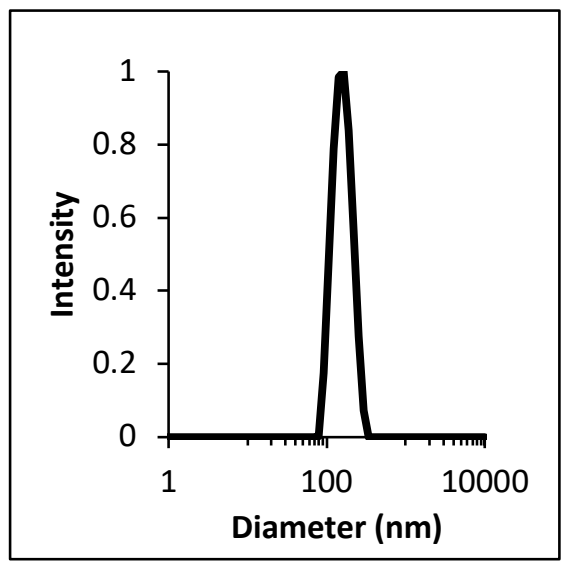




\section{III.Tetrablocks}

1. $S_{20}-\mathbf{D}_{20}-\mathbf{E}_{50}-\mathbf{F}_{20}$.

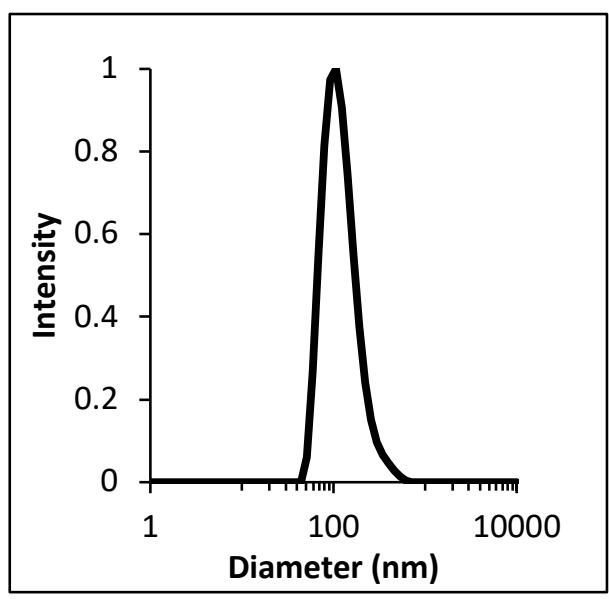

3. $\mathbf{S}_{30}-\mathbf{F}_{12}-\mathbf{D}_{20}-\mathbf{E}_{60}$

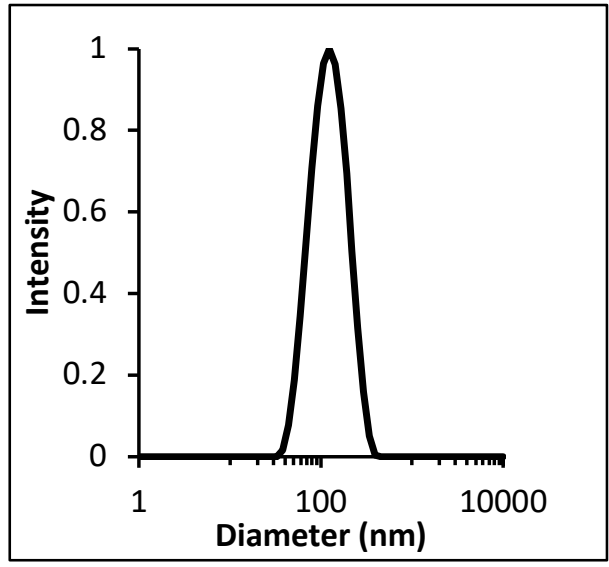

5. $E_{60}-S_{30}-F_{12}-D_{40}$

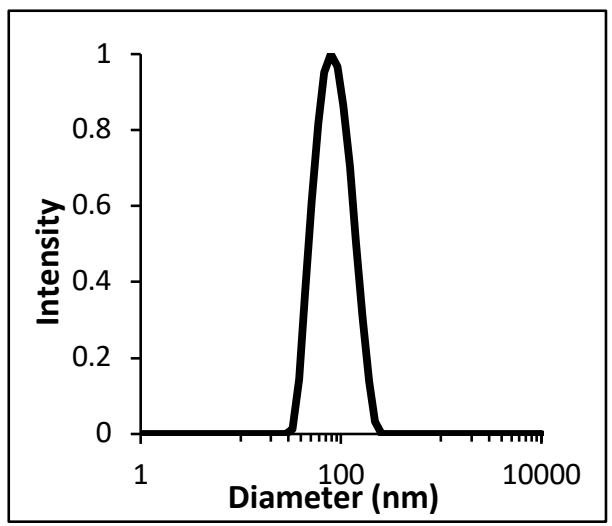

2. $\mathbf{F}_{20}-\mathbf{D}_{20}-\mathbf{E}_{50}-\mathbf{S}_{20}$

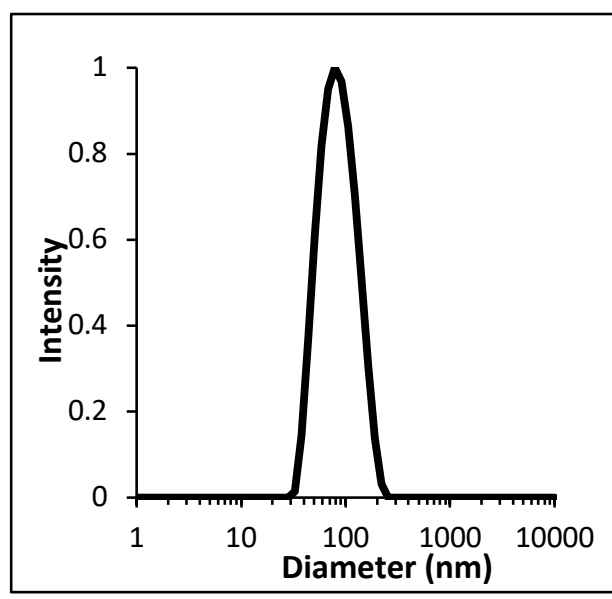

4. $E_{60}-S_{30}-F_{12}-D_{20}$

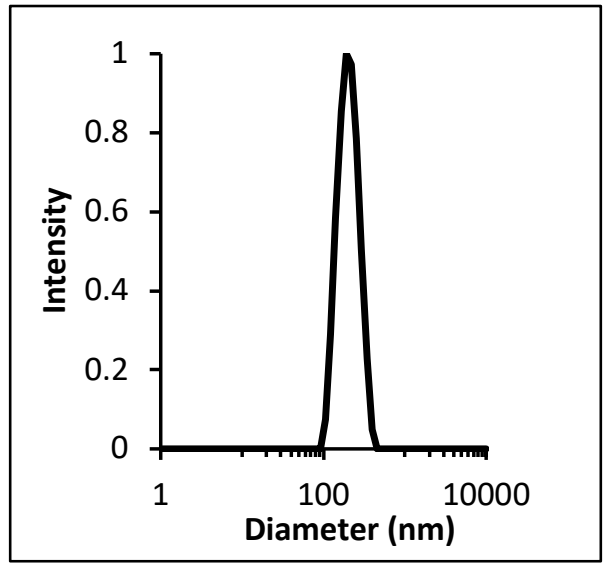

6. $\mathbf{S}_{30}-\mathbf{E}_{60}-\mathbf{F}_{12}-\mathbf{D}_{20}$

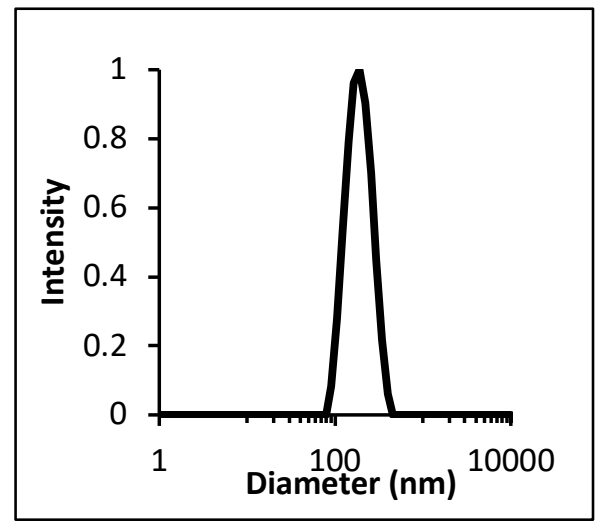

Figure S25. DLS traces of aqueous assembled bottlebrush copolymers corresponding to (Table S2 I, II and III). 


\section{CryoTEM images}

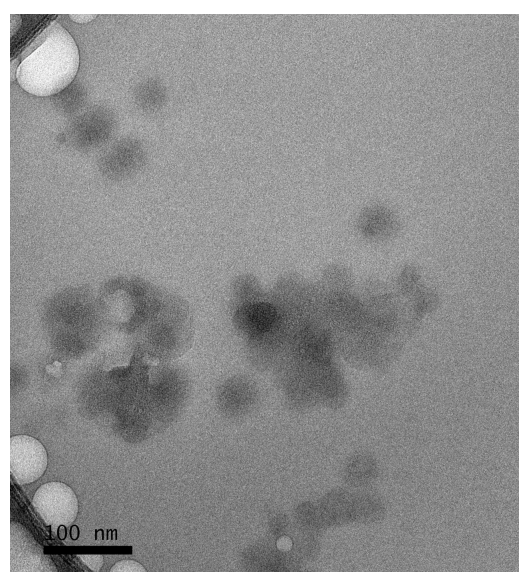

Figure S26. CryoTEM image of assembled nanostructures using $\mathbf{E}_{\mathbf{6 0}}-\mathbf{D}_{\mathbf{2 0}}$

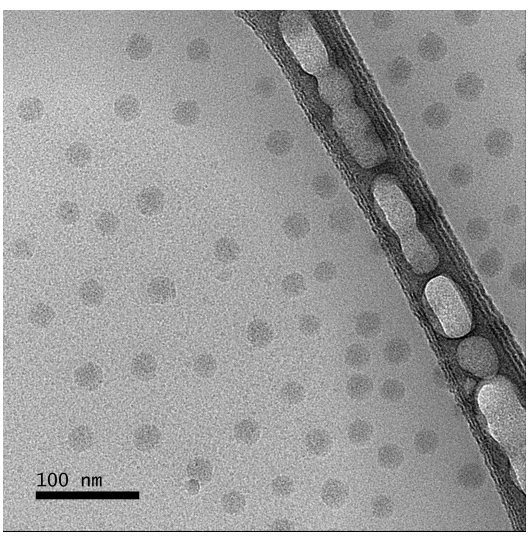

Figure S27. CryoTEM image of assembled nanostructures using $\mathbf{E}_{\mathbf{6 0}}-\mathbf{S}_{\mathbf{2 5}}$.

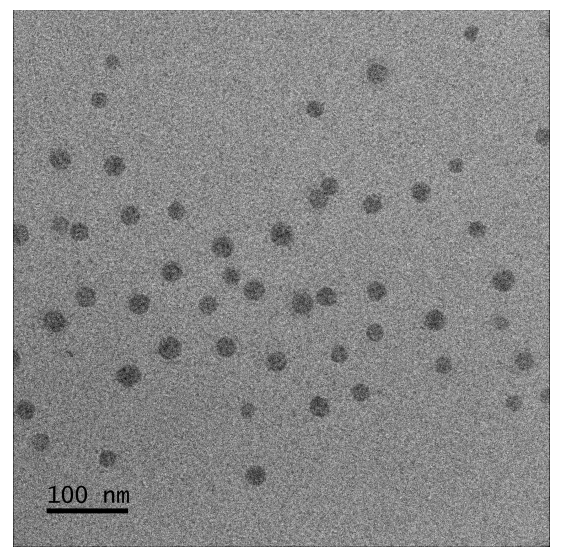

Figure S28. CryoTEM image of assembled nanostructures using $\mathbf{E}_{\mathbf{6 0}}-\mathbf{F}_{15}$. 


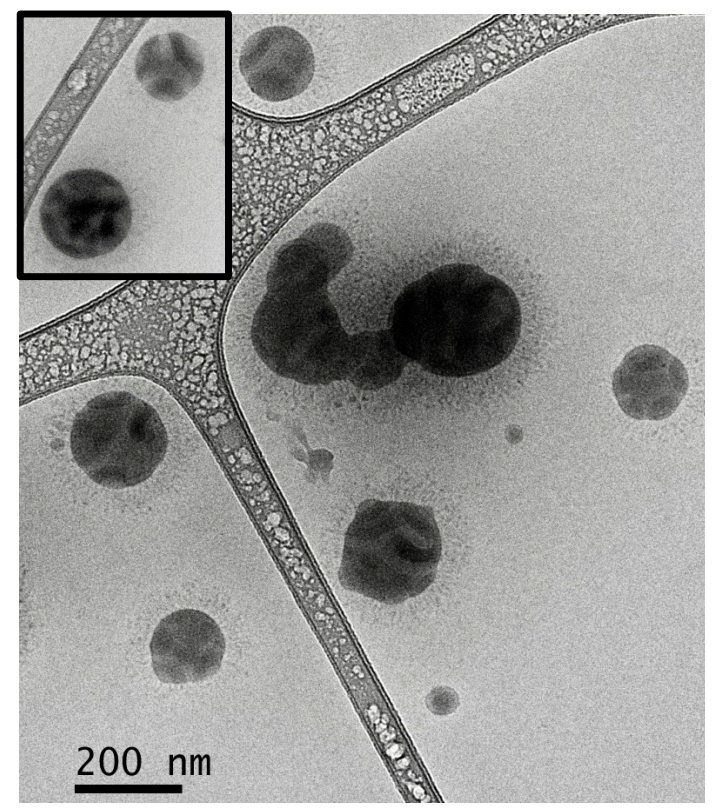

Figure S29. CryoTEM image of assembled nanostructures using $\mathbf{S}_{\mathbf{3 5}}-\mathbf{F}_{\mathbf{1 5}}-\mathbf{E}_{\mathbf{5 0}}$

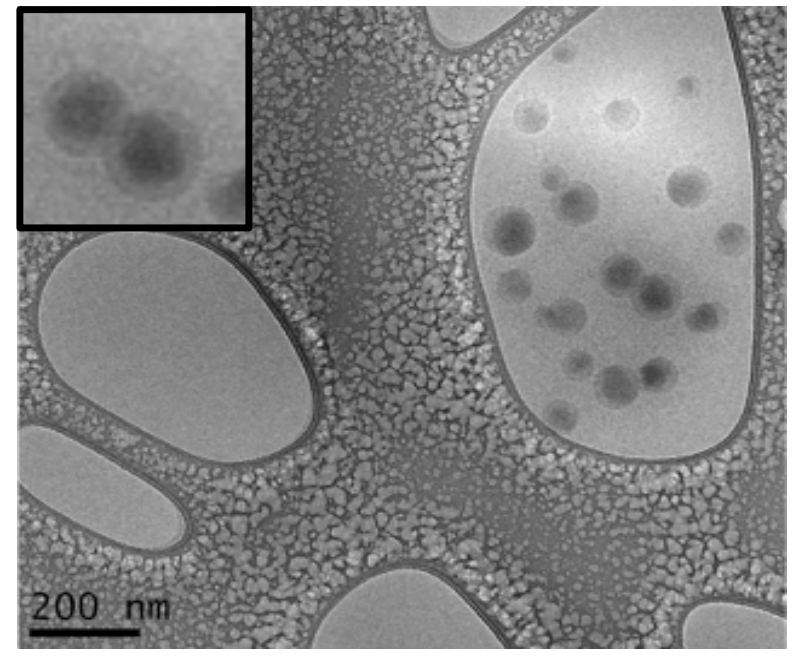

Figure S30. CryoTEM image of assembled nanostructures using $\mathbf{F}_{15}-\mathbf{E}_{\mathbf{5 0}}-\mathbf{S}_{\mathbf{3 5}}$ 


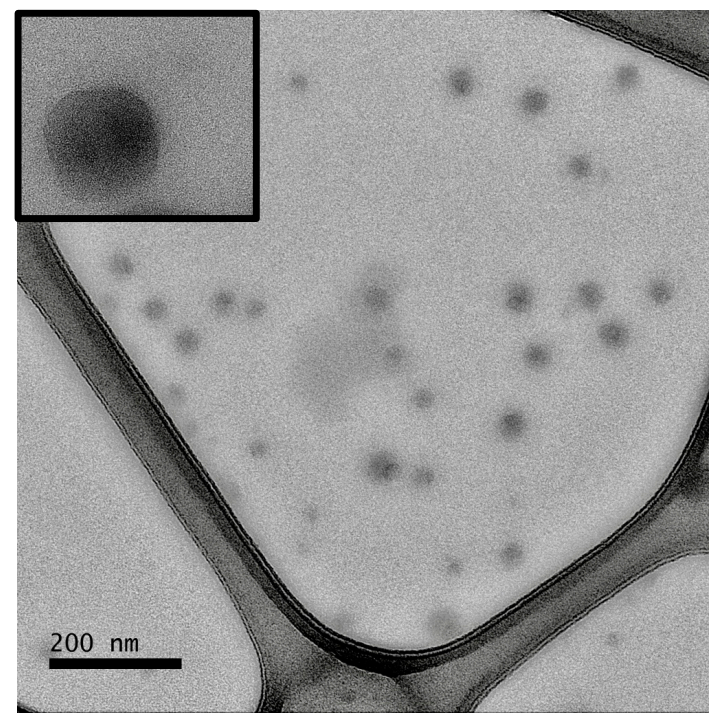

Figure S31. CryoTEM image of assembled nanostructures using $\mathbf{E}_{\mathbf{6 0}}-\mathbf{S}_{\mathbf{3 0}}-\mathbf{D}_{\mathbf{2 0}}$

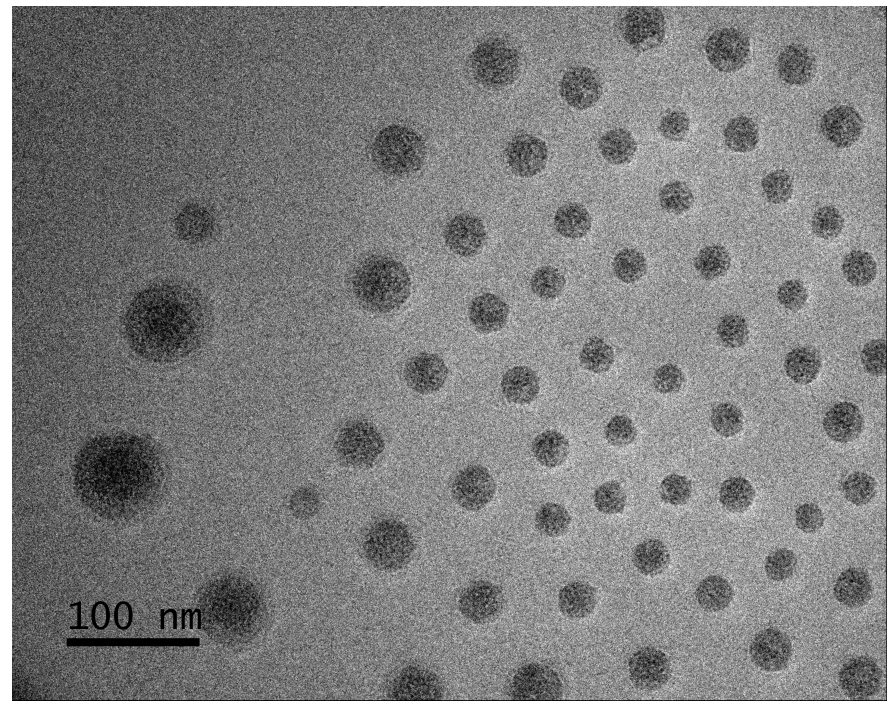

Figure S32. CryoTEM image of assembled nanostructures using $\mathbf{E}_{\mathbf{6 0}}-\mathbf{F}_{\mathbf{4 5}}-\mathbf{D}_{15}$ 


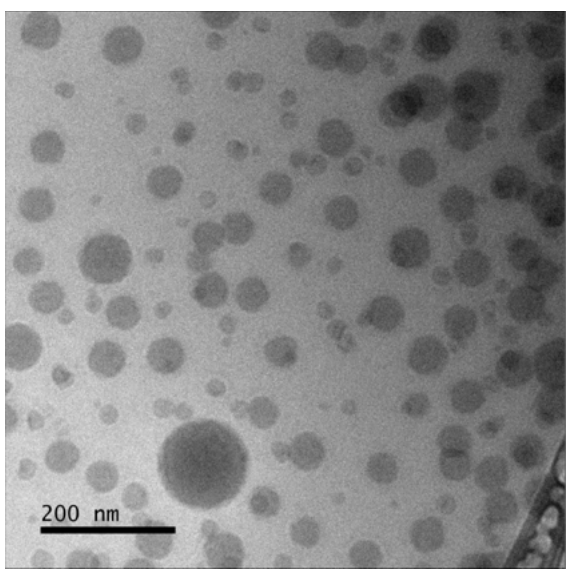

Figure S33. CryoTEM image of assembled nanostructures using $\mathbf{S}_{\mathbf{2 0}}-\mathbf{D}_{\mathbf{2 0}}-\mathbf{E}_{\mathbf{5 0}}-\mathbf{F}_{\mathbf{2 0}}$

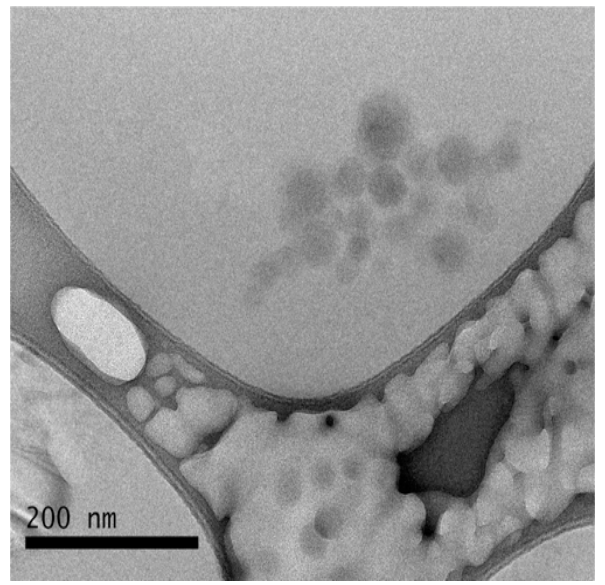

Figure S34. CryoTEM image of assembled nanostructures using $\mathbf{F}_{\mathbf{2 0}}-\mathbf{D}_{\mathbf{2 0}}-\mathbf{E}_{\mathbf{5 0}}-\mathbf{S}_{\mathbf{2 0}}$

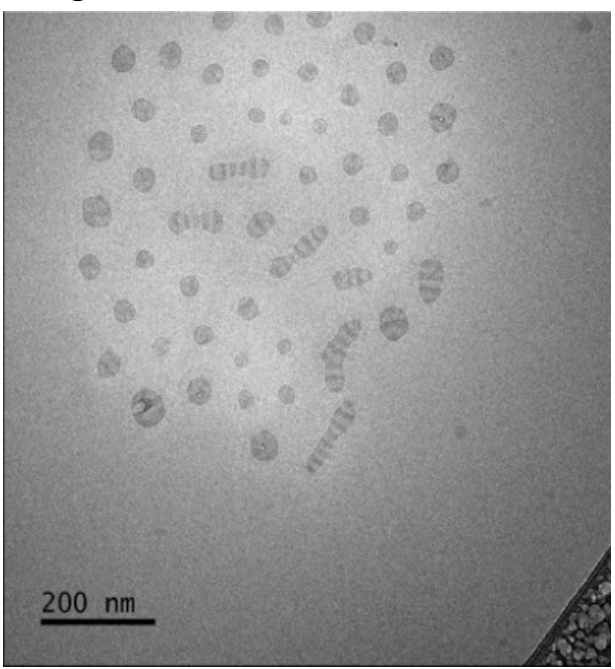

Figure S35. CryoTEM image of assembled nanostructures using $\mathbf{S}_{\mathbf{3 0}}-\mathbf{F}_{\mathbf{1 2}}-\mathbf{D}_{\mathbf{2 0}}-\mathbf{E}_{\mathbf{6 0}}$ 


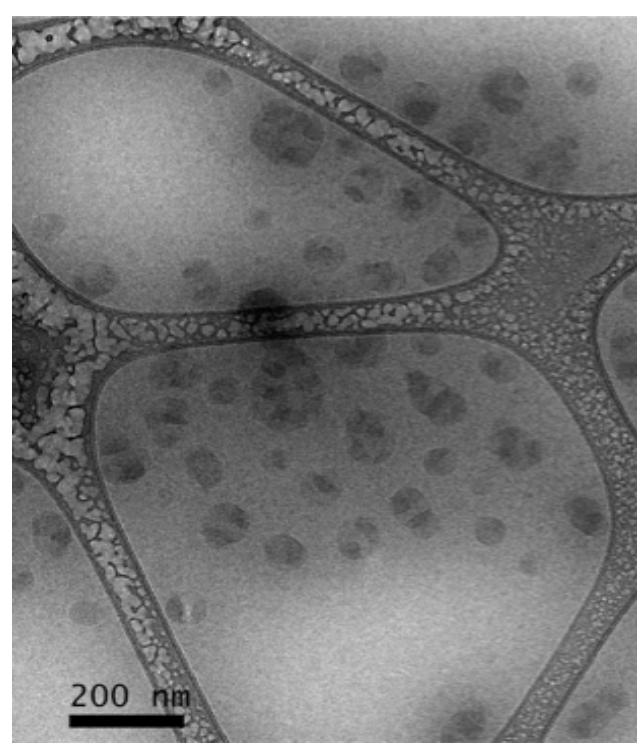

Figure S36. CryoTEM image of assembled nanostructures using $\mathbf{E}_{\mathbf{6 0}}-\mathbf{S}_{\mathbf{3 0}}-\mathbf{F}_{\mathbf{1 2}}-\mathbf{D}_{\mathbf{2 0}}$

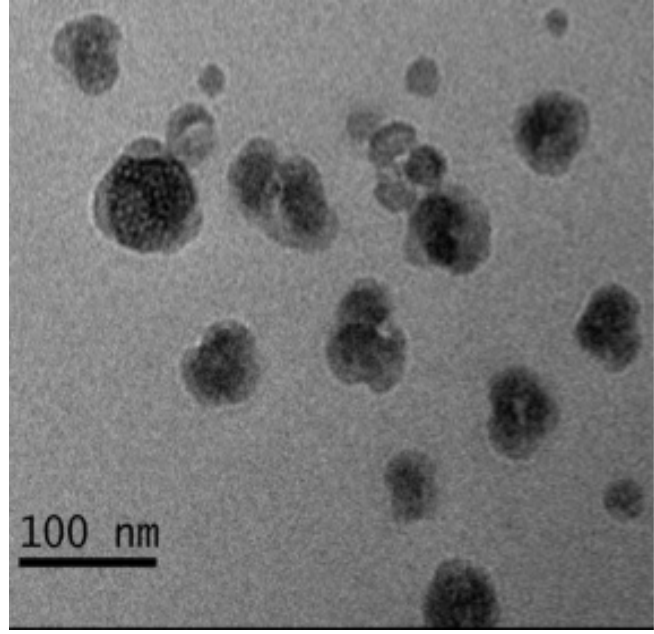

Figure S37. CryoTEM image of assembled nanostructures using $\mathbf{E}_{\mathbf{6 0}}-\mathbf{S}_{\mathbf{3 0}}-\mathbf{F}_{\mathbf{1 2}}-\mathbf{D}_{\mathbf{4 0}}$

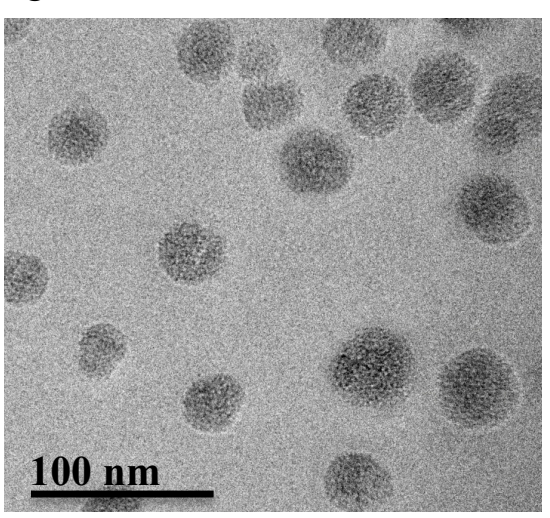

Figure S38. CryoTEM image of assembled nanostructures using $\mathbf{S}_{\mathbf{3 0}}-\mathbf{E}_{\mathbf{6 0}}-\mathbf{F}_{\mathbf{1 2}}-\mathbf{D}_{\mathbf{2 0}}$ 


\section{References}

1) Harris, R. K.; Becker, E. D.; Cabral de Menezes, S. M.; Goodfellow, R.; Granger, P., Solid State Nucl. Magn. Reson. 2002, 22, 458-483.

2) Sanford, M. S.; Love, J. A.; Grubbs, R. H., Organometallics 2001, 20, 5314-5318.

3) Chae, C.-G.; Yu, Y.-G.; Seo, H.-B.; Kim, M.-J.; Grubbs, R. H.; Lee, J.-S., Macromolecules 2018, 51, 3458-3466.

4) Yang, B.; Abel, B. A.; McCormick, C. L.; Storey, R. F., Macromolecules 2017, 50, 7458-7467.

5) Huang, Y.; Vezeridis, A. M.; Wang, J.; Wang, Z.; Thompson, M.; Mattrey, R. F.; Gianneschi, N. C., J. Am. Chem. Soc. 2017, 139, 15-18.

6) Sveinbjörnsson, B. R.; Weitekamp, R. A.; Miyake, G. M.; Xia, Y.; Atwater, H. A.; Grubbs, R. H., Proc. Natl. Acad. Sci. U.S.A 2012, 109, 14332-14336.

7) Bates, C. M.; Chang, A. B.; Momčilović, N.; Jones, S. C.; Grubbs, R. H., Macromolecules 2015, 48, 4967-4973.

8) Lin, T.-P.; Chang, A. B.; Chen, H.-Y.; Liberman-Martin, A. L.; Bates, C. M.; Voegtle, M. J.; Bauer, C. A.; Grubbs, R. H., J. Am. Chem. Soc. 2017, 139, 3896-3903.

(9) Erdodi, G.; Kennedy, J. P., J. Polym. Sci. Pol. Chem. 2005, 43, 4965-4971.

(10) Lee, J. N.; Park, C.; Whitesides, G. M., Anal. Chem. 2003, 75, 6544-6554.

(11) Marek, W. K.; Piątkowski, W.; Antos, D., Chromatographia 2018, 81, 1641-1648. 